\title{
Proteomic study of plaque fluid in high caries and caries free children
}

\author{
Weixu Chen ${ }^{\mathrm{a}}$, Zhiyan $\mathrm{He}^{\mathrm{b}, \mathrm{c}}$, Shujun Ran ${ }^{\mathrm{b}}$, Jingping Liang ${ }^{\mathrm{b}}$ and Wei Jiang ${ }^{\mathrm{b}, *}$ \\ ${ }^{a}$ Department of Stomatology, Eye and ENT Hospital of Fudan University, Shanghai, China \\ ${ }^{\mathrm{b}}$ Department of Endodontics and Operative Dentistry, Shanghai Ninth People's Hospital, College of \\ Stomatology, Shanghai Jiaotong University School of Medicine, National Clinical Research Center for \\ Oral Diseases, Shanghai Key Laboratory of Stomatology, Shanghai, China \\ 'Shanghai Research Institute of Stomatology, Ninth People's Hospital, School of Medicine, Shanghai \\ Jiao Tong University, Shanghai, China
}

\begin{abstract}
.
BACKGROUND: The occurrence and development of caries is a complex process affected by multiple factor.

OBJECTIVE: The present study was envisaged to evaluate the plaque fluid in caries free children and children with high caries, in order to establish a data set of bacterial secretion proteomics. A non-labeled quantitative technique based on two-dimensional liquid chromatography-series mass spectroscopy was employed to detect plaque fluid. Based on the proteomics data, the database search, data processing and pathway analysis illuminated the function of these proteins, and clarified the role of plaque microecology in caries occurrence and development.

METHODS: The study enrolled 8 caries free $(\mathrm{CF})$ children, whose decayed-missed-filled surface of teeth is $0(\mathrm{dmfs}=0)$, and caries sensitive (CS) children, whose decayed-missed-filled surface of teeth is $>10(\mathrm{dmfs}>10)(3 \sim 5$ years old $)$ for the smooth tooth plaque and the plaque in the high caries group. The plaque protein was extracted using the unlabeled quantitative technique like liquid chromatography-series mass spectrometry, using DeCyder ${ }^{\mathrm{TM}}$ MS Differential Analysis Software (version 1.0, GE Healthcare) that detected and compared the spectra, and quantified the full scanning before series mass spectroscopy. After obtaining all peptides with quantitative information, significantly differential polypeptide molecules were obtained $(p<0.05)$, and a metabolic pathway analysis was performed.

RESULTS: We identified 1,804 peptides with quantitative information, including 39 in CF, 30 in CS, and 1,735 similarly expressing peptides. After statistical analysis, 603 statistically different expression peptide data sets were obtained, including 202 high-expressed peptides in Group CF, 33 greater than 1.5 fold peptides, 401 high-expressed in Group CS and 199 greater than 1.5 fold peptide (173 nonredundant proteins).

CONCLUSION: Our study obtained the largest known dataset of the bacterial secretion protein in children with high caries, and screened the data set of high caries state. 603 peptides were statistically rich in 101 pathways, including glycolysis pyruvate acid metabolism, tricarboxylic acid cycle, pentyl phosphate pathway, fructose mannose metabolism, starch and sucrose metabolism, and $\mathrm{ABC}$ transporters.
\end{abstract}

Keywords: Proteomics, caries-free children, high caries children

\section{Introduction}

The occurrence and development of caries is a complex process affected by multiple factors, and reflects

\footnotetext{
${ }^{*}$ Corresponding author: Wei Jiang, Department of Endodontics and Operative Dentistry, Shanghai Ninth People's Hospital, Shanghai Jiaotong University School of Medicine; College of Stomatology; National Clinical Research Center for Oral Diseases; Shanghai Key Laboratory of Stomatology, No. 639, Zhizaoju Road, Shanghai 200011, China. Tel.: +86 21 23271699 5282; Fax: +86216313 5412; E-mail: jiangweishanghai@126.com.
}

0928-7329 (c) 2022 - The authors. Published by IOS Press. This is an Open Access article distributed under the terms of the Creative Commons Attribution-NonCommercial License (CC BY-NC 4.0). 
the composition of microorganisms that is often not constant, but undergoes continuous dynamic changes. It also depends on the complexity of the interaction between the bacteria and the host. The functions within the plaque are not performed by a single individual organism, but involve the entire microbial community. However, in the current stomatology research, people's understanding of the micro-ecology is often based on the single microbial species purely cultivated in the laboratory, or the interaction of several limited species, and the understanding of the microbial community as a whole is far behind the understanding of its individuals.

The emergence of macroproteomics provides a good platform for a comprehensive research on the plaque protein components, but it is equally challenging. The first step of sample preparation, including the complete extraction of the bacterial intracellular and extracellular proteins in the plaque, is one of the major bottlenecks. In the extracellular environment where bacterial cells survive, the plaque fluid is the forefront of the bacteria interaction, host-specific and non-specific immunity, and is relatively easy for the separation and purification process, thereby being one of the ideal models for the research on caries. By analyzing the differences in the protein composition of the plaque in children without caries and those with high caries, the impact of between the plaque and host on the occurrence and development process of caries in children can be more intuitively and accurately explored.

To accomplish this, the study employed the non-labeled quantitative technology based on twodimensional liquid chromatography-series mass spectrometry to analyze the plaque fluid in children without caries and children with high caries and established a data set of bacterial secretion proteomics. On this basis, using database search, data processing and pathway analysis, it further clarified the role of plaque microecology in the occurrence and development of caries.

\section{Materials and methods}

\subsection{Sampling}

According to the third version of the caries diagnosis standard of the Basic Methods of WHO Oral Health Survey, 8 children (CF, dmfs $=0)$ and CS, dmfs $>10(3 \sim 10)$ were selected respectively, without any oral diseases, systemic health, and no history of medication (including fluorogens) in March, 2020.

The children required no oral hygiene care on the night before sampling, starting from the morning, and $12 \mathrm{~h}$ fasting and drinking before sampling. Washing the collection area with sterile saline. Avoid moisture with cotton roll. In CF group, we scraped all the dental plaque of smooth suface of deciduous molar teeth. In CS group, we scraped all the healthy smooth enamel surface [1,2]. The parents of the child knowingly agreed for the experimental procedure.

\subsection{Preparation of plaque sample}

The plaque was collected in a pre-cooled $0.5 \mathrm{ml}$ centrifuge tube in crushed ice and immediately sent to the laboratory and centrifuged at $4^{\circ} \mathrm{C}, 15,000 \mathrm{~g}$ for 60 minutes to remove the bacteria, insoluble impurities and other substances, and the supernatant liquid obtained was the plaque fluid [3]. The plaque fluid was carefully transferred into the new EP tube, a protease inhibitor (Inhibitor cocktail complete, Roche) was added, and the concentrate was collected with the Millipore (cutoff: $5 \mathrm{KD}$ ) ultrafiltration tube at $4{ }^{\circ} \mathrm{C}$, 4500 g. Quantitative protein concentration of the centrifugal fluid was done by Bradford (Bio-Rad, USA), and stored at $-80^{\circ} \mathrm{C}[4,5]$. 


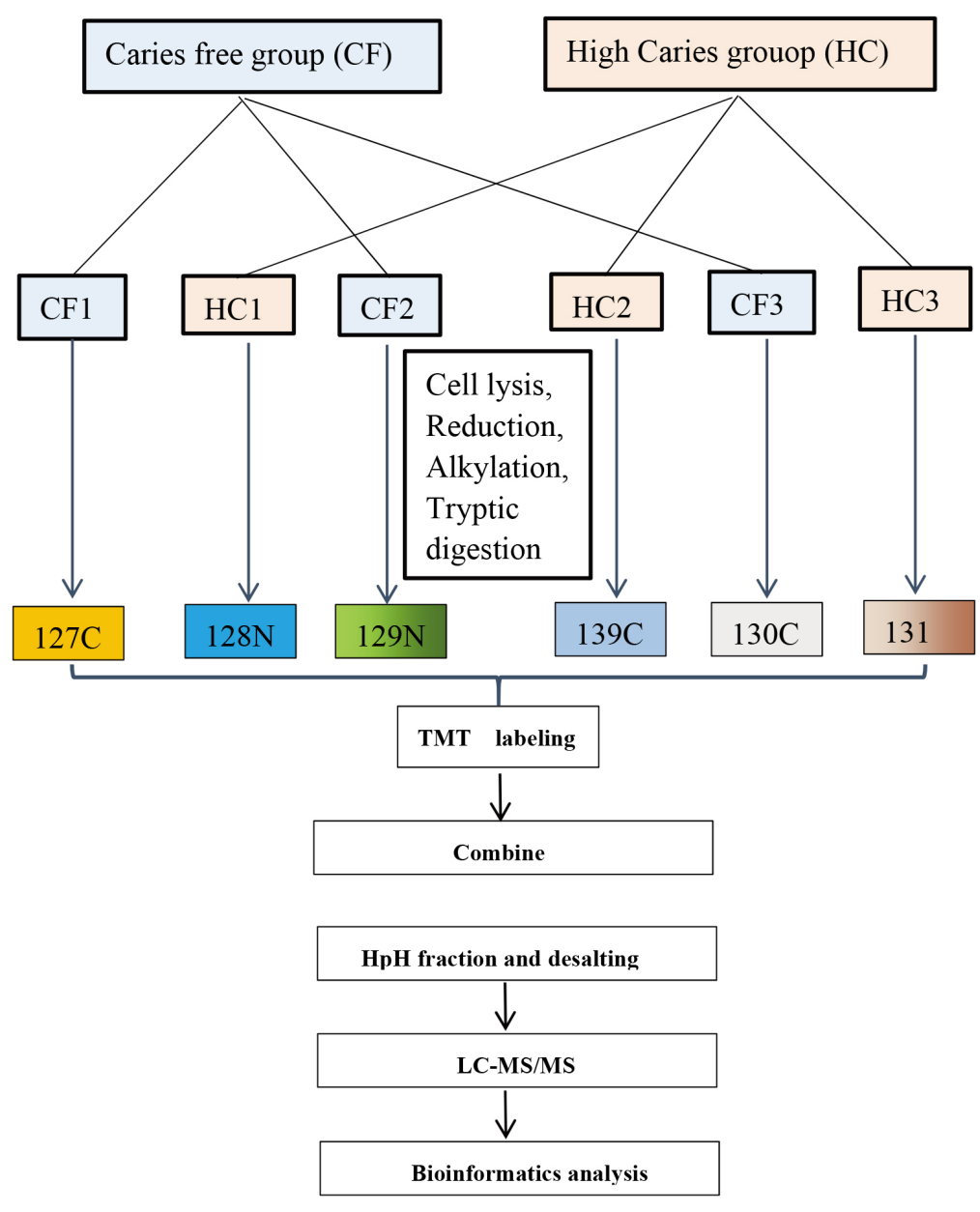

Fig. 1. Experimental workflow for TMT labeling and analysis: TMT 10-plex labeling was performed for three sets of technical replicates. Each condition was labeled as follows for the three technical replicates: CF (127N, 129N, 130C), HC (128N, 139C, 131). Moreover, equally amount of proteins from all samples were pooled as an internal standard (IS: 126). The labeled fractions were combined and subjected to High-pH Reversed-Phase Fractionation and desalting, followed by separation using liquid chromatography mass spectrometry (LC-MS/MS), and bioinformatics data analysis.

\subsection{Preparation of enzyme solution}

In order to reduce the differences between the individuals, the plaque proteins of the children without caries and children with high caries were mixed in equal amounts, and a sample library was established. $\mathrm{CF}$ and CS plaque were divided into three parts..Each protein samples were supplemented with lysis buffer ( $8 \mathrm{~mol} / \mathrm{Lurea}, 40 \mathrm{mmol} / \mathrm{L}$ Tris, $65 \mathrm{mmol} / \mathrm{L}$ DTT) to the total volume of $100 \mu \mathrm{l}$, and mixed with $1 \mathrm{M}$ DTT at $37^{\circ} \mathrm{C}$ for 2.5 hours. Subsequently, $10 \mu 11 \mathrm{M} \mathrm{IAA}$, was added at room temperature in absence of light and the reaction was continued for 40 minutes. After the above treatment, the protein was completely deformed, the disulfide bond opened up. It was then precipitated with a $5 \mathrm{x}$ volume of precooled acetone $\left(-20^{\circ} \mathrm{C}\right)$ by resting overnight $(16$ hours $)$ at $-20^{\circ} \mathrm{C}$. Then, the mixture was centrifuged at $14,000 \mathrm{~g}$ for 40 minutes; the organic solvent was removed using pre-cooled acetone at $-20^{\circ} \mathrm{C}$, centrifuged again at $14,000 \mathrm{~g}$ for 40 minutes. To remove the salt ions, precooled $70 \%$ ethanol $\left(-20^{\circ} \mathrm{C}\right)$ was added and 


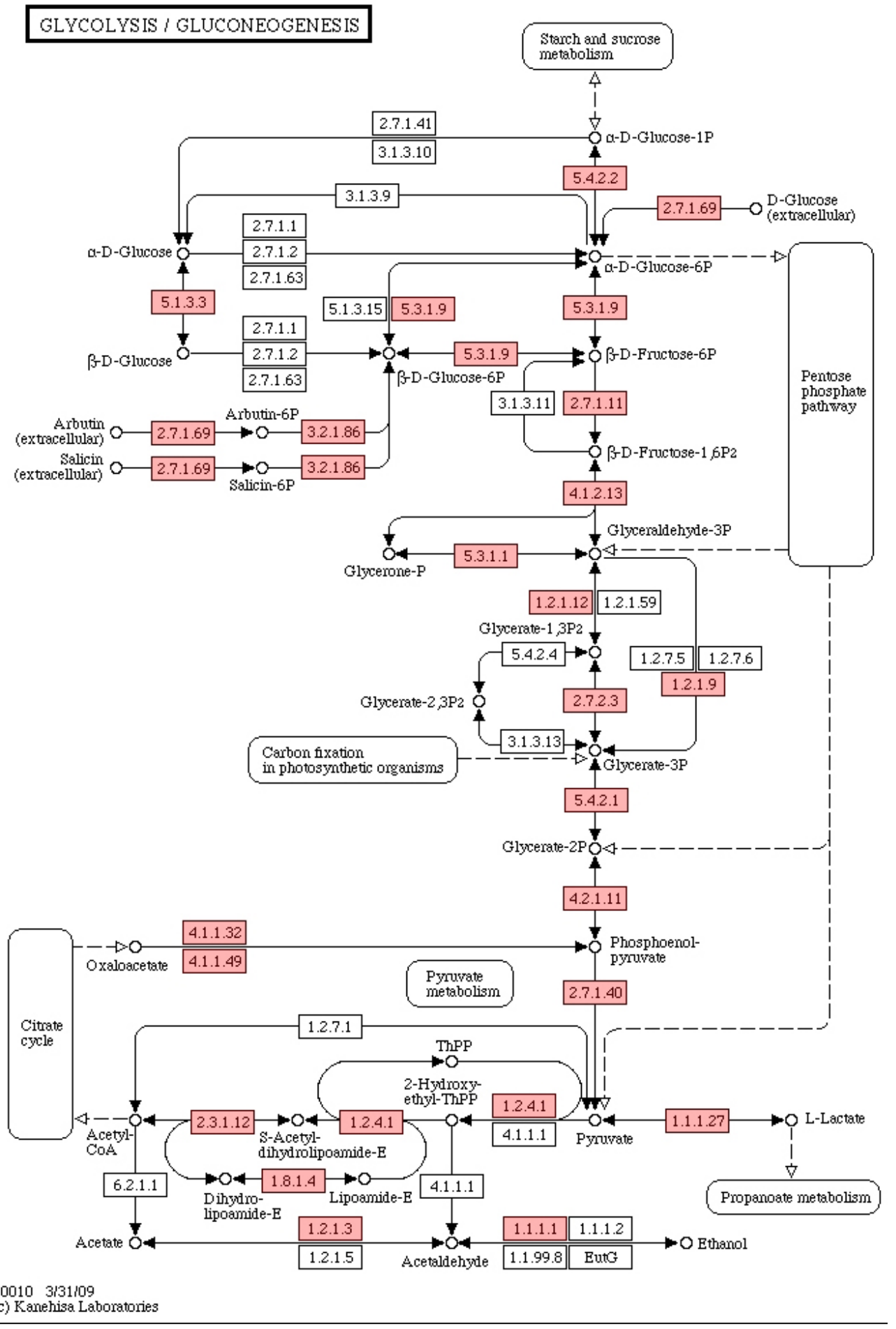

Fig. 2. Glycolysis/Gluconeogenesis. 
PYRUVATE METABOLISM

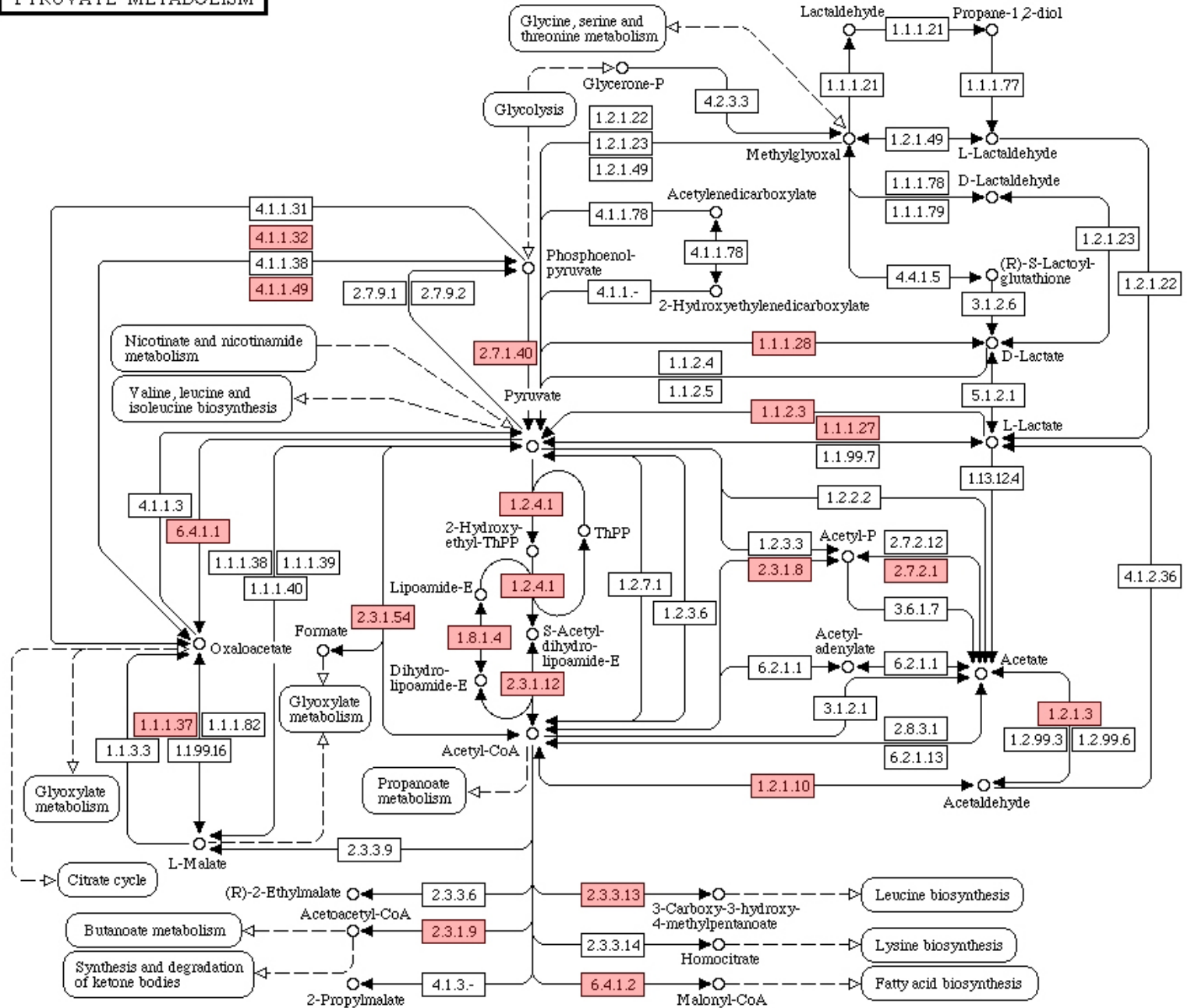

006205121109

(c) Kanehisa Laboratories

Fig. 3. Pyruvate metabolism.

centrifuged at 14,000 g for 40 minutes and then freeze dried. After the enzyme solution was completed, the ultrafiltration membrane was employed with Millipore $10 \mathrm{KD}$ aperture size to collect the filter fluid and freeze dried at $-80^{\circ} \mathrm{C}$.

\subsection{Liquid chromatography-mass spectrometry analysis}

$20 \mu \mathrm{g}$ of the prepared enzyme solutions were taken and analyzed using the Ettan MDLC liquid chromatography-series mass spectroscopy system (GE Healthcare, Piscataway, NJ, USA). RP trap columns (Zorbax 300 SBC 18, Agilent Technologies, Palo Alto, CA, USA) were employed with an automatic sample feeder. The sample was desalted using the $\mathrm{C} 18$ trap column. The sample was separated on the $\mathrm{C} 18$ column (Millipore water in A phase and $0.1 \%$ FA 84\% B finishing water solution, at a gradient 
CITRATE CYCLE (TCA CYCLE)

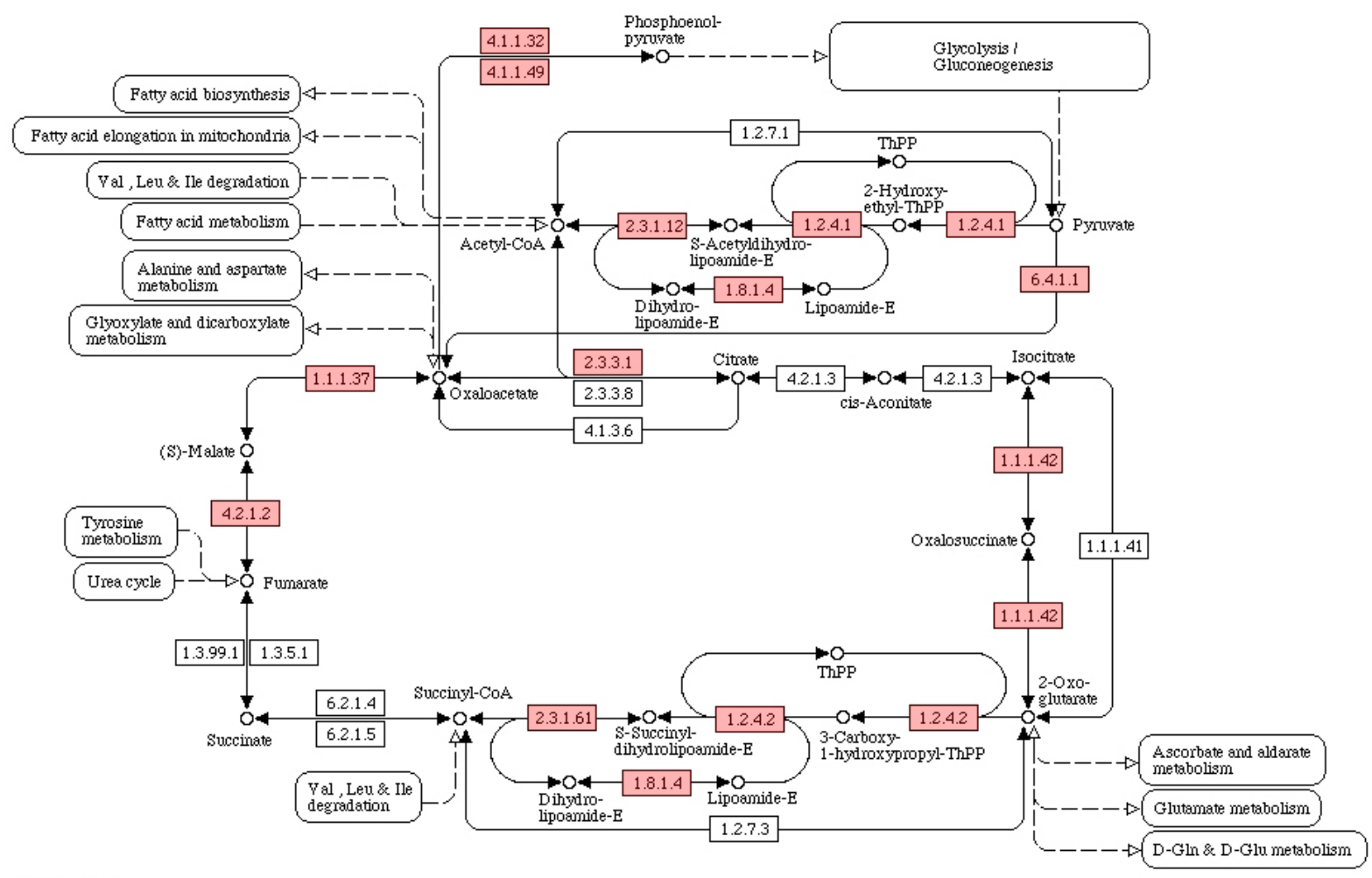

000205118109

(c) Kanehisa Laboratories

Fig. 4. Tricarboxylic acid cycle.

rising from $4 \%$ to $50 \%$ B phase within 2 hours). The separation speed was $2 \mu \mathrm{l} / \mathrm{min}$. The samples were removed from the column, and subjected directly to electric spray source ${ }^{\mathrm{TM}} \mathrm{LTQ}^{\mathrm{TM}}$ Linear ion-trap mass spectrometry (Thermo Electron, San Jose, CA, USA). The LTQ mass spectrometry was performed in the automatic gain control (AGC) mode, with the ion source parameters set as: electric spray voltage $3.2 \mathrm{kV}$; capillary temperature $-170^{\circ} \mathrm{C}$. Full-scan mass spectrograms were collected in the profile mode, while MS/MS maps were collected in the centroid mode, with 5 centroid mode scans after each profile mode. The analysis was repeated 3 times per sample.

\subsection{Database search and data processing}

After obtaining all peptides with quantitative information, It was tested for all $p<0.05$, and searched with the SEQUEST program (Bioworks Browser Software suite, Thermo Electron, version 3.1) at the National Center for Biotechnology Information (www.ncbi.nlm.nih.gov) based on the genome information of 24 common oral bacteria in Genome. It was downloaded to get the corresponding protein sequence database (24 common oral bacteria including Streptococcus gordonii str. Challis substr. CH1, Streptococcus mutans UA159, Streptococcus sanguinis SK36, Streptococcus salivarius SK126, Actinomyces odontolyticus ATCC 17982, Lactobacillus acidophilus, Lactobacillus fermentum, Neisseria mucosa ATCC 25996, Neisseria sicca ATCC 29256, Neisseria subflava NJ9703, Veillonella dispar ATCC 17748, 


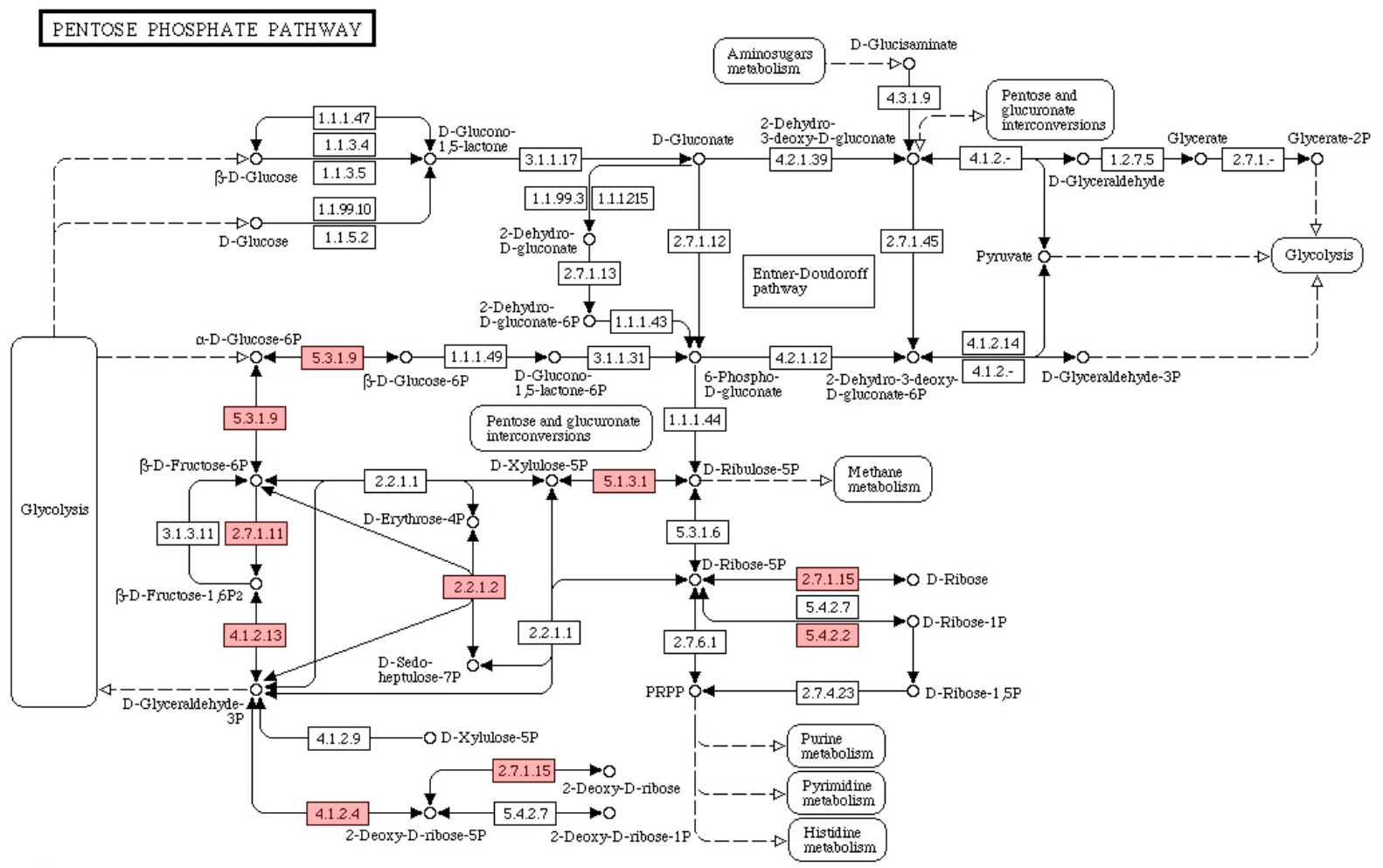

Fig. 5. Pentose phosphate pathway.

Veillonella parvula DSM 2008, Corynebacterium matruchotii, Corynebacterium diphtheriae NCTC 13129, Leptotrichia buccalis DSM 1135, Eikenella corrodens ATCC 23834, Porphyromonas gingivalis, Prevotella melaninogenica ATCC 25845, Capnocytophaga gingivalis ATCC 33624, Capnocytophaga ochracea DSM 7271, Capnocytophaga sputigena ATCC 33612, Fusobacterium nucleatum, Treponema denticola ATCC 35405, Campylobacter rectus RM3267). The polypeptide molecules were identified and their corresponding proteins were relatively quantified. The filter parameters were: when Charge +1 , Xcorr $\geqslant 1.9$; when Charge +2 , Xcorr $\geqslant 2.2$; when Charge + 3, Xcorr $\geqslant 3.75$; where DelCN $\geqslant 0.1$.

\subsection{Pathway analysis}

The metabolic pathway map was downloaded for the 24 common oral bacteria from the www.kegg.com website to analyze the distribution of the identified proteins in each pathway.

\subsection{Microbial function and pathway analysis}

All identified microbial protein sequences were annotated by BLASTP (version: 2.2.31+) against the UniProtKB/Swiss-Prot database that included 560,118 sequences and the COG database (version: 2014) that included 1,781,653 sequences. Furthermore, InterProScan (version: 5.35-74.0) provided the gene ontology (GO) functional annotations of all identified microbial protein sequences with default parameters. Some in-house Perl scripts and R scripts were used to complete the GO functional classification and 


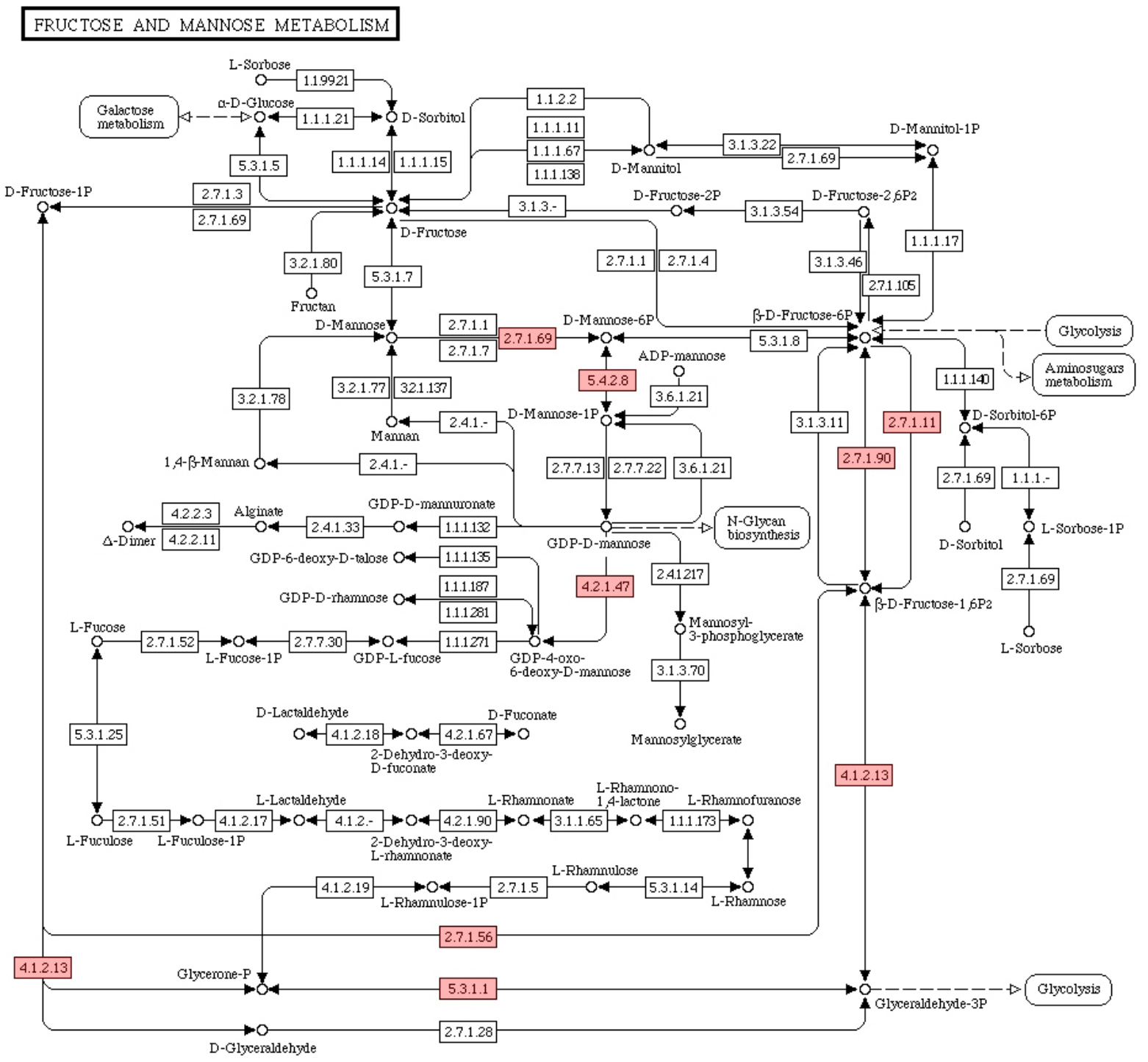

$00051 \quad 614109$

(c) Kanehisa Laboratories

Fig. 6. Fructose mannose metabolism.

statistics analysis. The KEGG orthology (KO) annotation of the proteins were performed using KOBAS (version: 3.0) with E-value $<=1 \mathrm{e}-05$ and $\operatorname{rank}<=5$. Moreover, KOBAS was also used to perform a binomial test between the two groups in the KEGG pathway levels. Assignment of the proteins in the KEGG pathway levels was then visualized with Krona Excel Template.

\subsection{PRM verification}

Based on the results of the original label-free based quantitative meta-proteomics analysis, we selected the appropriate target peptides of the candidate proteins and performed targeted shotgun MS to finally determine the peptides of the target proteins with reliable identification information, which was used 


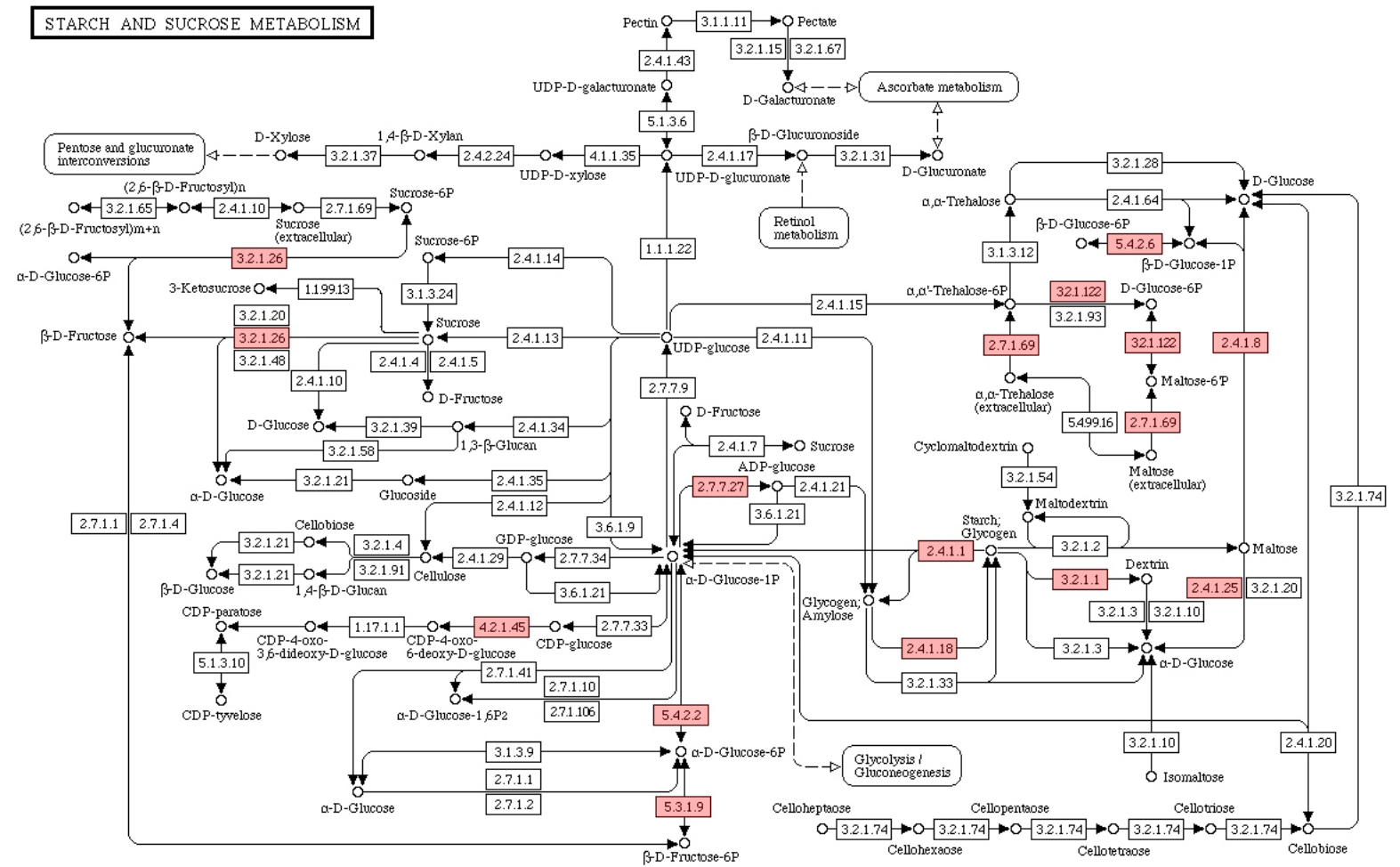

Fig. 7. Fructose mannose metabolism.

in the PRM quantification analysis. The peptide information suitable for PRM analysis was imported into the Xcalibur software program for PRM setup. Briefly, $1 \mu \mathrm{g}$ peptide from each sample was taken for LC-PRM/MS analysis. After sample loading, chromatographic separation was performed using a Thermo Scientific EASY-nLC nano-HPLC system. The following buffer was used: A solution was $0.1 \%$ formic acid aqueous solution and solution B was a mixed solution of $0.1 \%$ formic acid, acetonitrile, and water (95\% of acetonitrile). The column was first equilibrated with $95 \%$ A solution. The sample was injected into a Trap column $(100 \mu \mathrm{m} \times 20 \mathrm{~mm}, 5 \mu \mathrm{m}-\mathrm{C} 18$, Dr. Maisch $\mathrm{GmbH})$ and subjected to gradient separation through a chromatography column $(75 \mu \mathrm{m} \times 150 \mathrm{~mm}, 3 \mu \mathrm{m}-\mathrm{C} 18$, Dr. Maisch GmbH $)$ at a flow rate of $250 \mathrm{~nL} / \mathrm{min}$. The liquid phase separation gradient was as follows: 0-25 minutes, linear gradient of B liquid from 5\% to $18 \%$; 25-45 minutes, linear gradient of B liquid from 18\% to 50\%; 45-48 minutes, linear gradient of B liquid from 50\% to $95 \%$; and 48-60 minutes, B liquid maintained at $95 \%$. The peptides were separated and subjected to targeted PRM/MS using a Q-Exactive mass spectrometer (Thermo Scientific). The analysis time was $60 \mathrm{~min}$. The parameters were set as follows: detection mode positive; parent ion scanning range $-350-1500 \mathrm{~m} / \mathrm{z}$; capillary voltage $-1.8 \mathrm{kv}$; isolation width $-1.6 \mathrm{Th}$; first-order MS resolution - 70,000 @ m/z 200; AGC target - 3e6; first-level maximum IT - 250 ms. Peptide secondary MS was performed as follows: for each full scan, target peptides of the precursor $\mathrm{m} / \mathrm{z}$ were sequentially selected based on the inclusion list for second-order MS (MS2) scan with the parameters as follows: resolution - 35,000@ m/z 200; AGC target - 3e6; Level 2 Maximum IT - 120 ms; MS2 Activation Type - HCD; Peptide fragmentation - nitrogen; Isolation window - 2.0 Th; Normalized collision energy $-28 \mathrm{eV}$. The obtained PRM data of the raw RAW file was analyzed using the Skyline 3.5 
Table 1

High expression of bacterial secretory protein in plaque fluid of caries free children $(>1.5$ fold)

\begin{tabular}{|c|c|c|c|c|}
\hline NUM & Mass (Da) & Av. Ratio & Protein & ID Details \\
\hline 1 & 2019.2246 & 3.9419625 & gi|34763016 & Nicotinate-nucleotide pyrophosphorylase \\
\hline 2 & 1627.0841 & 3.9031119 & gi|228274697 & ISPg2, transposase \\
\hline 3 & 844.77333 & 3.1448998 & gi 229211250 & uncharacterized conserved protein \\
\hline 4 & 2015.8037 & 2.6245635 & gi 228277090 & competence protein \\
\hline 5 & 1308.9237 & 2.53298 & gi 197736798 & hypothetical protein FNP_1346 \\
\hline 6 & 1485.0629 & 2.1089494 & gi| 213962598 & ribosome recycling factor \\
\hline 7 & 1004.8306 & 1.965104 & gi 223039105 & selenium metabolism protein YedF \\
\hline 8 & 1583.1056 & 1.9346806 & gi 229255033 & predicted extracellular nuclease \\
\hline 9 & 1528.0214 & 1.9116673 & gi|229211921 & peroxiredoxin \\
\hline 10 & 1594.8706 & 1.8001297 & gi|229255138 & outer membrane protein \\
\hline 11 & 1369.6639 & 1.7949729 & gi 34763038 & NADH dehydrogenase reductase \\
\hline 12 & 1495.2313 & 1.793346 & gi 188995429 & hypothetical protein PGN_1565 \\
\hline 13 & 1328.7801 & 1.7567087 & gi 228275526 & peptide chain release factor 2 \\
\hline 14 & 1043.2649 & 1.7419186 & gi| 226710238 & ribosomal protein L15 \\
\hline 15 & 1289.2159 & 1.7255517 & gi|229210576 & chaperone protein DnaK \\
\hline 16 & 905.04655 & 1.6972979 & gi|223039140 & GTP-binding protein TypA/BipA \\
\hline 17 & 1814.3222 & 1.696517 & gi|228277158 & cell division protein FtsA \\
\hline 18 & 1341.9164 & 1.6860124 & gi 229210533 & glutamate dehydrogenase/leucine dehydrogenase \\
\hline 19 & 1614.0495 & 1.6716142 & gi|223038584 & carbamoyl-phosphate synthase, large subunit \\
\hline 20 & 1347.1639 & 1.6420553 & gi 42527896 & Jag protein, putative \\
\hline 21 & 1434.1841 & 1.6119828 & gi| 229210576 & chaperone protein DnaK \\
\hline 22 & 1440.6899 & 1.6006457 & gi|34762754 & Alkyl hydroperoxide reductase $\mathrm{C} 22$ \\
\hline 23 & 1583.0756 & 1.599004 & gi|223039559 & VirB10 \\
\hline 24 & 1296.9619 & 1.5660363 & gi|229210802 & glyceraldehyde-3-phosphate dehydrogenase \\
\hline 25 & 1414.2779 & 1.561902 & gi 229212600 & LSU ribosomal protein L15P \\
\hline 26 & 1743.6774 & 1.5616289 & gi 223039552 & 3-phosphoshikimate 1-carboxyvinyltransferase \\
\hline 27 & 1438.047 & 1.5568823 & gi| 238058718 & Phosphoserine aminotransfera \\
\hline 28 & 913.14203 & 1.5564213 & gi|229212593 & LSU ribosomal protein L5P \\
\hline 29 & 714.50116 & 1.5434605 & gi|229254206 & outer membrane protein \\
\hline 30 & 888.51295 & 1.5399202 & gi|229210548 & fructose-bisphosphate aldolase \\
\hline 31 & 1254.5932 & 1.5356884 & gi|223039512 & phosphoribosylaminoimidazole carboxylase \\
\hline 32 & 1383.4912 & 1.5141757 & gi| 223038622 & protein TolB \\
\hline 33 & 1366.1202 & 1.5058051 & gi|213963395 & putative outer membrane protein \\
\hline
\end{tabular}

software program. Statistical analysis was completed with R and the 'MetaboAnalystR' package.

Data availability: All the MS raw files were submitted to the Proteome Xchange Consortium (http://www.proteomexchange.com) via the PRIDE partner repository with the data set identifier.

\subsection{Statistical analysis}

Statistical analysis was performed using the SPSS version 19 software. The experiments were statistically analyzed with the independent sample T test. All statistical analysis were performed at $95 \%$ significance level using 2-tailed analysis.

\section{Results}

\subsection{Label-free 2D-LC-MS/MS Identification}

Liquid chromatography-series mass were analyzed in CF, CS group (we repeated the experiments for three times), including 1804 quantitative information peptides, 39 in CF group, and 30 in CS group. The 


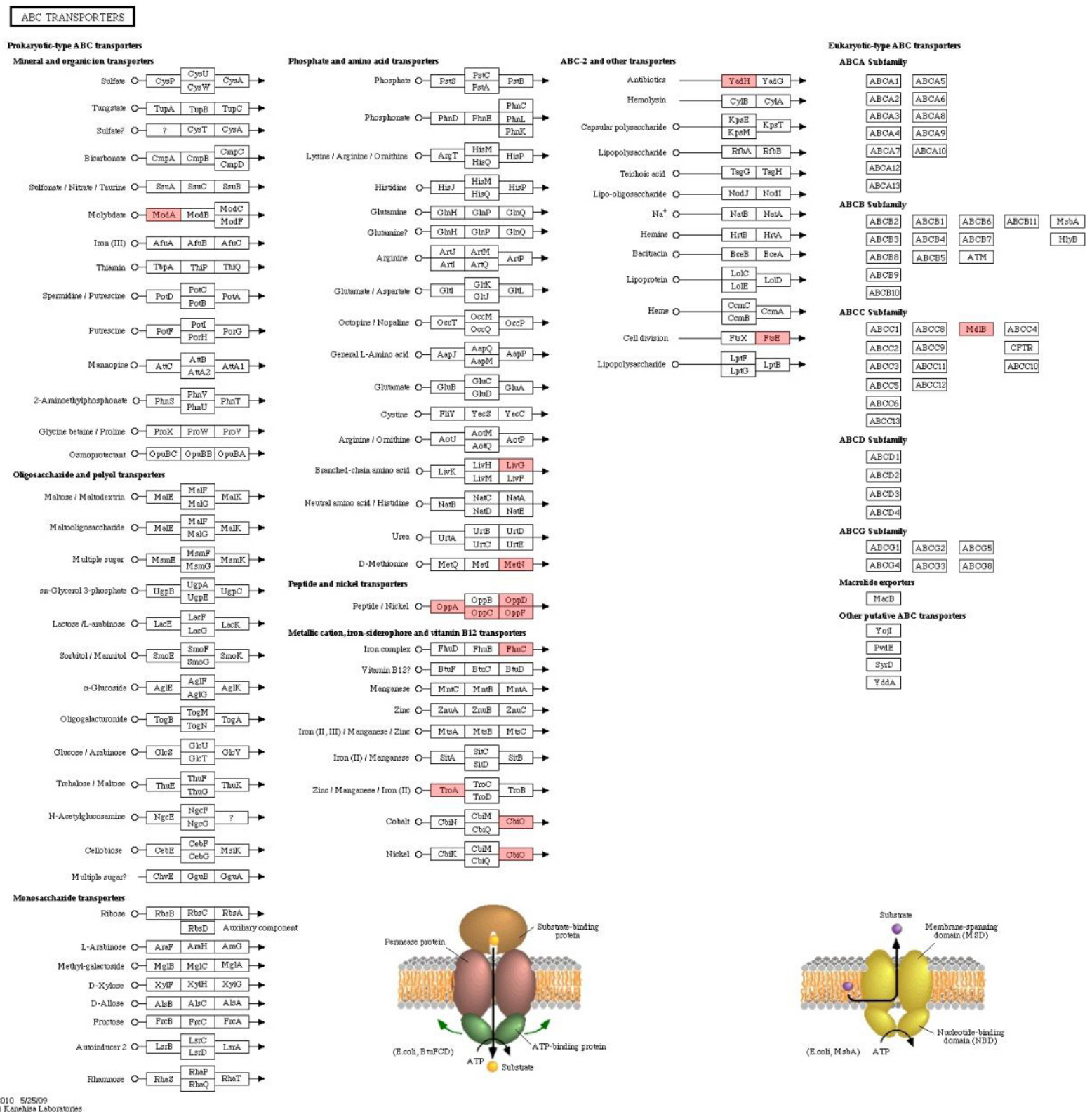

Fig. 8. ABC transport proteins.

$$
\mathrm{C}_{6} \mathrm{H}_{12} \mathrm{O}_{6}+2 \mathrm{NAD}^{+}+2 \mathrm{ADP}+2 \mathrm{H}_{3} \mathrm{PO}_{4} \rightarrow 2 \mathrm{NADH}+2 \mathrm{C}_{3} \mathrm{H}_{4} \mathrm{O}_{3}+2 \mathrm{ATP}+2 \mathrm{H}_{2} \mathrm{O}+2 \mathrm{H}^{+}
$$

Fig. 9. Glycolysis reaction formula.

data from liquid chromatography-series mass spectroscopy was analyzed by DecyderMS software, and 603 peptide data sets were obtained, including 202 in CF group. Among them, 33 peptide has a much higher significant differences which was greater than 1.5 times (Table 1), On the other hand, we found 
Table 2

High expression of bacterial secretory protein in plaque fluid of high caries children( $>1.5$ fold $)$

\begin{tabular}{|c|c|c|c|c|}
\hline NUM & Mass (Da) & Av. ratio & Protein & ID details \\
\hline 1 & 2968.55 & 14.07 & gi|229210864 & pyruvate kinase \\
\hline 2 & 1921.24 & 5.88 & gi| 225023847 & hypothetical protein EIKCOROL_00713 \\
\hline 3 & 1652.71 & 5.62 & 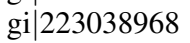 & GTP cyclohydrolase II \\
\hline 4 & 2016.63 & 4.81 & gi $\mid 229211338$ & D-3-phosphoglycerate dehydrogenase \\
\hline 5 & 2463.40 & 4.80 & gi| 213964012 & glyceraldehyde-3-phosphate dehydrogenase \\
\hline 6 & 2076.89 & 4.54 & gi|229211633 & bacterial nucleoid protein $\mathrm{Hbs}$ \\
\hline 7 & 1760.03 & 3.97 & gi| 228276851 & signal transduction sensor histidine kinase \\
\hline 8 & 1702.16 & 3.60 & gi 42526786 & Fe-hydrogenase large subunit family protein \\
\hline 9 & 2008.27 & 3.29 & gi 42527800 & galactokinase, putative \\
\hline 10 & 1399.83 & 3.16 & gi| 229255924 & glycosyltransferase \\
\hline 11 & 1767.07 & 3.14 & gi 228274481 & CobN/magnesium chelatase family protein \\
\hline 12 & 2283.30 & 3.00 & gi|229210533 & glutamate dehydrogenase/leucine dehydrogenase \\
\hline 13 & 1969.37 & 2.96 & gi| 229255585 & conserved hypothetical protein YmdA/YtgF \\
\hline 14 & 2120.52 & 2.89 & gi 229211673 & aminotransferase [Leptotrichia buccalis DSM 11 \\
\hline 15 & 1141.80 & 2.73 & gi 42527828 & cobyric acid synthase CobQ, putative \\
\hline 16 & 1420.06 & 2.68 & gi 223039292 & periplasmic nitrate reductase, large subunit \\
\hline 17 & 2206.43 & 2.68 & gi 213962023 & translation elongation factor $\mathrm{Tu}$ \\
\hline 18 & 1793.18 & 2.60 & gi 228274858 & alpha-glucosidase \\
\hline 19 & 1989.89 & 2.59 & gi|229212231 & Ser-tRNA (Thr) hydrolase; threonyl-tRNA synthet \\
\hline 20 & 1680.71 & 2.55 & gi 34763824 & Butyrate-acetoacetate CoA-transferase subunit B \\
\hline 21 & 2506.35 & 2.55 & gi 229212304 & Phospho-N-acetylmuramoyl-pentapeptide-transfer \\
\hline 22 & 2490.59 & 2.52 & gi| 229212655 & theronine dehydrogenase-like Zn-dependent dehy \\
\hline 23 & 1848.55 & 2.52 & gi $\mid 197737364$ & flavoprotein [Fusobacterium nucleatum subsp. \\
\hline 24 & 2545.12 & 2.45 & gi| 197736680 & ESS family glutamate:sodium $(\mathrm{Na}+)$ symporter \\
\hline 25 & 2168.04 & 2.41 & gi 42527533 & OmpA family protein \\
\hline 26 & 1420.07 & 2.40 & gi 229212277 & galactose-6-phosphate isomerase lacB subunit \\
\hline 27 & 2550.84 & 2.36 & gi|229210656 & PTS system IIA component \\
\hline 28 & 2574.22 & 2.36 & gi $\mid 229212275$ & tagatose-bisphosphate aldolase \\
\hline 29 & 2477.69 & 2.35 & gi 228275593 & glyceraldehyde-3-phosphate dehydrogenase, type I \\
\hline 30 & 2337.25 & 2.33 & gi 228275800 & translation elongation factor $\mathrm{Ts}$ \\
\hline 31 & 1390.89 & 2.28 & gi|34763496 & Transposase \\
\hline 32 & 1972.36 & 2.27 & gi| 228275746 & All-trans-retinol 13,14-reductase \\
\hline 33 & 1893.57 & 2.26 & gi|42525942 & bacteriocin $\mathrm{ABC}$ transporter, bacteriocin-binding \\
\hline 34 & 1683.48 & 2.24 & gi $\mid 42528037$ & hypothetical protein TDE2537 \\
\hline 35 & 2116.25 & 2.22 & gi $\mid 197735845$ & heat shock protein $\mathrm{HtpG}$ \\
\hline 36 & 1961.89 & 2.21 & gi 229211604 & glycerol dehydrogenase-like oxidoreductase \\
\hline 37 & 2130.66 & 2.21 & gi| 228274607 & lysine-tRNA ligase \\
\hline 38 & 2056.26 & 2.20 & gi 42525700 & $\mathrm{ABC}$ transporter, ATP-binding protein \\
\hline 39 & 1595.09 & 2.19 & gi 197735846 & fructose-bisphosphate aldolase \\
\hline 40 & 1629.07 & 2.19 & gi|229212489 & Zn-dependent alcohol dehydrogenase \\
\hline 41 & 1747.08 & 2.18 & gi 42525562 & TPR domain-containing protein \\
\hline 42 & 2085.76 & 2.14 & gi 188994038 & probable transcriptional regulator $\mathrm{AraC}$ famil \\
\hline 43 & 2455.92 & 2.13 & gi $\mid 188994275$ & thiol-disulfide interchange protein \\
\hline 44 & 1789.44 & 2.11 & gi| 229211224 & 2-isopropylmalate synthase \\
\hline 45 & 1753.58 & 2.11 & gi 228275128 & thiol-disulfide isomerase and thioredoxin \\
\hline 46 & 1565.07 & 2.10 & gi 229212393 & PTS system IIC component; diguanylate phosphod \\
\hline 47 & 1764.52 & 2.09 & gi| 223039902 & methionine import ATP-binding protein MetN \\
\hline 48 & 1865.75 & 2.07 & gi 228275077 & 2,3-bisphosphoglycerate-dependent phosphoglycerate \\
\hline 49 & 1873.80 & 2.06 & gi 34762210 & DNA integration/recombination/invertion protein \\
\hline 50 & 1716.11 & 2.06 & gi $\mid 19703909$ & putative cytoplasmic protein \\
\hline 51 & 1608.73 & 2.05 & gi 228274448 & ribosomal protein $\mathrm{S} 6$ \\
\hline 52 & 1938.30 & 2.04 & gi $\mid 223039930$ & isocitrate dehydrogenase, NADP-dependent \\
\hline 53 & 2109.28 & 2.04 & gi|34396499 & hypothetical protein PG_0355 \\
\hline
\end{tabular}


Table 2, continued

\begin{tabular}{|c|c|c|c|c|}
\hline NUM & Mass (Da) & Av. ratio & Protein & ID details \\
\hline 54 & 1830.82 & 2.03 & gi|34764184 & Fructose-bisphosphate aldolase \\
\hline 55 & 2032.14 & 2.03 & gi 229211623 & aspartate semialdehyde dehydrogenase \\
\hline 56 & 2093.27 & 2.02 & gi 34763916 & Phage protein [Fusobacterium nucleatum subsp. v \\
\hline 57 & 1721.75 & 2.00 & gi|225024749 & hypothetical protein EIKCOROL_01635 \\
\hline 58 & 2060.16 & 2.00 & gi 34762309 & Aspartate carbamoyltransferase \\
\hline 59 & 2051.33 & 1.99 & gi|229210854 & bacterial nucleoid protein $\mathrm{Hbs}$ \\
\hline 60 & 1689.00 & 1.99 & gi|225025771 & hypothetical protein EIKCOROL_02675 \\
\hline 61 & 2109.08 & 1.99 & gi|213962365 & GDP-mannose 4,6-dehydratase \\
\hline 62 & 1984.14 & 1.99 & gi 229210454 & hypothetical protein LebuDRAFT 02810 \\
\hline 63 & 1769.30 & 1.99 & gi 229212758 & DNA/RNA helicase, superfamily II, SNF2 family \\
\hline 64 & 1982.31 & 1.98 & gi 34762754 & Alkyl hydroperoxide reductase $\mathrm{C} 22$ \\
\hline 65 & 1604.10 & 1.97 & gi 225025378 & hypothetical protein EIKCOROL_02276 \\
\hline 66 & 2352.23 & 1.96 & gi|229210734 & nickel $\mathrm{ABC}$ transporter, periplasmic nickel-bin \\
\hline 67 & 1801.25 & 1.96 & gi $\mid 229211277$ & triosephosphate isomerase \\
\hline 68 & 2169.29 & 1.94 & gi 42525820 & hypothetical protein TDE0304 \\
\hline 69 & 1956.47 & 1.94 & gi| 42528183 & RNA polymerase sigma factor WhiG \\
\hline 70 & 2003.22 & 1.92 & gi 34763262 & DNA helicase \\
\hline 71 & 1580.18 & 1.91 & gi 213962986 & conserved hypothetical protein \\
\hline 72 & 1634.89 & 1.90 & gi 42526801 & TldD/PmbA family protein \\
\hline 73 & 1813.18 & 1.89 & gi 34762500 & hypothetical protein \\
\hline 74 & 1473.49 & 1.89 & gi|229256034 & CRISPR-associated protein, Csn1 family \\
\hline 75 & 1917.00 & 1.88 & gi|225025193 & hypothetical protein EIKCOROL_02088 \\
\hline 76 & 1764.27 & 1.88 & gi|229212814 & SSU ribosomal protein $\mathrm{S} 30 \mathrm{P}$ \\
\hline 77 & 1695.78 & 1.86 & gi|42525831 & $\mathrm{ABC}$ transporter ATP-binding protein/peptidase \\
\hline 78 & 1892.92 & 1.86 & gi 213962338 & isocitrate dehydrogenase, NADP-dependent \\
\hline 79 & 1714.29 & 1.86 & gi|213963684 & probable transcriptional regulatory protein, $\mathrm{C}$ \\
\hline 80 & 1484.02 & 1.86 & gi|229211130 & glycogen/starch/alpha-glucan phosphorylase \\
\hline 81 & 1812.44 & 1.86 & gi 228275794 & conserved hypothetical protein \\
\hline 82 & 1759.24 & 1.85 & gi|213962889 & conserved hypothetical protein \\
\hline 83 & 1302.12 & 1.85 & gi 229254579 & hypothetical protein CochDRAFT_08810 \\
\hline 84 & 1912.25 & 1.85 & gi 213962806 & apolipoprotein $\mathrm{N}$-acyltransferase \\
\hline 85 & 1840.92 & 1.85 & gi 197735467 & ABC superfamily ATP binding cassette transpor \\
\hline 86 & 2159.33 & 1.84 & gi 42526405 & $\mathrm{ABC}$ transporter, ATP-binding protein \\
\hline 87 & 1523.07 & 1.83 & gi|229211940 & phosphoglycerate kinase \\
\hline 88 & 2126.30 & 1.83 & gi| 34762663 & Phosphoglycerate kinase \\
\hline 89 & 1890.45 & 1.82 & gi|228275464 & isoleucine-tRNA ligase \\
\hline 90 & 2015.12 & 1.82 & gi 34762786 & CDP-glucose 4,6-dehydratase \\
\hline 91 & 1447.57 & 1.82 & gi|229211563 & uncharacterized conserved protein \\
\hline 92 & 1468.71 & 1.82 & gi|34763070 & tRNA (Uracil-5-) -methyltransferase \\
\hline 93 & 1811.06 & 1.82 & gi 197736083 & hypothetical protein FNP_0608 \\
\hline 94 & 1769.04 & 1.81 & gi| 223038758 & outer membrane lipoprotein \\
\hline 95 & 2322.33 & 1.81 & gi 225024644 & hypothetical protein EIKCOROL_01521 \\
\hline 96 & 1898.96 & 1.81 & gi| 34762648 & GTP-binding protein TypA/BipA TypA/BipA \\
\hline 97 & 1754.57 & 1.80 & gi 213963724 & dihydrolipoyl dehydrogenase \\
\hline 98 & 2038.83 & 1.80 & gi| 34762615 & Hypothetical Cytosolic Protein \\
\hline 99 & 1804.83 & 1.79 & gi| 228276477 & conserved hypothetical protein \\
\hline 100 & 1720.61 & 1.79 & gi 197735629 & hypothetical protein FNP_0141 \\
\hline 101 & 1255.86 & 1.79 & gi|223039442 & ATP-dependent DNA helicase RecG \\
\hline 102 & 2159.84 & 1.78 & gi|34764317 & Flavodoxin \\
\hline 103 & 1949.98 & 1.77 & gi| 197736855 & glutamate formimidoyltransferase \\
\hline 104 & 1735.95 & 1.77 & gi|229210412 & nonphosphorylating glyceraldehyde-3-phosphate \\
\hline 105 & 1417.96 & 1.77 & gi 19703626 & DNA polymerase III alpha subunit \\
\hline 106 & 2435.47 & 1.76 & gi|225023733 & hypothetical protein EIKCOROL_00597 \\
\hline
\end{tabular}


Table 2, continued

\begin{tabular}{|c|c|c|c|c|}
\hline NUM & Mass (Da) & Av. ratio & Protein & ID details \\
\hline 107 & 1952.19 & 1.76 & gi| 197735760 & copper $(\mathrm{Cu} 2+)$-exporting ATPase \\
\hline 108 & 1946.13 & 1.75 & gi| 34762728 & Enolase \\
\hline 109 & 2044.80 & 1.75 & gi| 228275814 & fructose-bisphosphate aldolase, class II \\
\hline 110 & 2101.11 & 1.74 & gi 225023349 & hypothetical protein EIKCOROL_00207 \\
\hline 111 & 1870.30 & 1.73 & gi 188995942 & mannose-1-phosphate guanylyltransferase \\
\hline 112 & 1815.15 & 1.72 & gi 228275794 & conserved hypothetical protein \\
\hline 113 & 2065.65 & 1.72 & gi 229211517 & sulfite reductase, beta subunit (hemoprotein) \\
\hline 114 & 2144.06 & 1.72 & gi|229210391 & signal transduction histidine kinase, COG0642 \\
\hline 115 & 1444.38 & 1.72 & gi 223038512 & hypothetical protein CAMRE0001_0295 \\
\hline 116 & 1681.92 & 1.71 & gi| 188995759 & hypothetical protein PGN_1895 \\
\hline 117 & 1946.32 & 1.70 & gi 229211610 & uncharacterized paraquat-inducible protein B \\
\hline 118 & 1982.21 & 1.70 & gi|229212544 & phosphoribosylformylglycinamidine synthase \\
\hline 119 & 1928.05 & 1.70 & gi $\mid 213962314$ & hypothetical protein CAPSP0001_0185 \\
\hline 120 & 2053.30 & 1.69 & gi 42525700 & $\mathrm{ABC}$ transporter, ATP-binding protein \\
\hline 121 & 1674.50 & 1.69 & gi 229211928 & $\mathrm{Fe}-\mathrm{S}$ oxidoreductase \\
\hline 122 & 2025.65 & 1.68 & gi 197737300 & possible plasmid mobilization protein \\
\hline 123 & 2124.28 & 1.67 & gi 229211402 & D-isomer specific 2-hydroxyacid dehydrogenase \\
\hline 124 & 2205.30 & 1.66 & gi 213963583 & conserved hypothetical protein \\
\hline 125 & 1460.65 & 1.66 & gi 42527134 & glycine cleavage system $\mathrm{H}$ protein \\
\hline 126 & 1899.49 & 1.66 & gi $\mid 188994568$ & putative tonB-linked outer membrane receptor \\
\hline 127 & 1541.42 & 1.66 & gi $\mid 213963481$ & glycogen synthase \\
\hline 128 & 1887.21 & 1.64 & gi 197736995 & 3-dehydroquinate synthase \\
\hline 129 & 1273.98 & 1.64 & gi| 228274891 & conserved hypothetical protein \\
\hline 130 & 1657.53 & 1.63 & gi 197736095 & pyruvate synthase [Fusobacterium nucleatum su \\
\hline 131 & 1483.78 & 1.63 & gi| 229211272 & hypothetical protein LebuDRAFT_11420 \\
\hline 132 & 2134.60 & 1.62 & gi|228276496 & ribosomal protein $\mathrm{S} 3$ \\
\hline 133 & 1618.98 & 1.62 & gi 197736759 & $\mathrm{~N}$-acyl-D-aspartate/D-glutamate deacylase \\
\hline 134 & 1782.11 & 1.61 & gi|34397232 & DNA-binding protein, histone-like family \\
\hline 135 & 1586.32 & 1.61 & gi 42526652 & phage minor structural protein, putative \\
\hline 136 & 1693.94 & 1.61 & gi $\mid 197736825$ & hypothetical protein FNP_1373 [Fusobacterium \\
\hline 137 & 2148.12 & 1.61 & gi 197735216 & elongation factor EF1A \\
\hline 138 & 2002.16 & 1.61 & gi 225025671 & hypothetical protein EIKCOROL_02573 \\
\hline 139 & 1480.44 & 1.60 & gi 188994351 & FtsK/SpoIIIE family cell division protein \\
\hline 140 & 1816.96 & 1.60 & gi 19703982 & putative cytoplasmic protein \\
\hline 141 & 1776.34 & 1.59 & gi 42527210 & hypothetical protein TDE1704 \\
\hline 142 & 2021.76 & 1.59 & gi 42526714 & integrase/recombinase XerD \\
\hline 143 & 2098.43 & 1.59 & gi| 225024872 & hypothetical protein EIKCOROL_01760 \\
\hline 144 & 1480.96 & 1.58 & gi|213964056 & aspartyl-tRNA synthetase \\
\hline 145 & 1712.68 & 1.57 & gi|213962204 & hypothetical protein CAPSP0001_1551 \\
\hline 146 & 1874.39 & 1.57 & gi|225023233 & hypothetical protein EIKCOROL_00085 \\
\hline 147 & 1494.21 & 1.57 & gi| 229210434 & UDP-N-acetylmuramyl tripeptide synthase \\
\hline 148 & 1673.82 & 1.56 & gi 19705272 & 4-amino-4-deoxychorismate lyase \\
\hline 149 & 1951.21 & 1.56 & gi| 42525731 & TPR domain-containing protein \\
\hline 150 & 2204.99 & 1.56 & gi 228274869 & chaperone protein DnaK \\
\hline 151 & 1590.11 & 1.56 & gi| 188993943 & hypothetical protein PGN_0079 \\
\hline 152 & 1601.16 & 1.56 & gi 42527320 & hypothetical protein TDE1814 \\
\hline 153 & 1889.49 & 1.56 & gi|42528104 & hypothetical protein TDE2604 \\
\hline 154 & 1664.98 & 1.55 & gi 223039847 & fructose-1,6-bisphosphatase \\
\hline 155 & 1377.94 & 1.55 & gi| 34764886 & Export $\mathrm{ABC}$ transporter \\
\hline 156 & 2059.94 & 1.55 & gi| 34762866 & hypothetical protein \\
\hline 157 & 2792.72 & 1.55 & gi| 229212597 & LSU ribosomal protein L18P [Leptotrichia bucca \\
\hline 158 & 1143.01 & 1.55 & gi| 229212654 & hypothetical protein LebuDRAFT_25250 \\
\hline 159 & 1772.95 & 1.54 & gi 228276146 & hypothetical protein CAPGI0001_0708 \\
\hline 160 & 1601.40 & 1.54 & gi| 188995090 & ribonucleotide reductase \\
\hline
\end{tabular}


Table 2, continued

\begin{tabular}{cccll}
\hline NUM & Mass (Da) & Av. ratio & \multicolumn{1}{c}{ Protein } & ID details \\
\hline 161 & 1885.91 & 1.54 & gi $\mid 42527008$ & hypothetical protein TDE1500 \\
162 & 1999.21 & 1.54 & gi $\mid 42527772$ & methyl-accepting chemotaxis protein \\
163 & 1859.62 & 1.54 & gi 229212449 & McrBC 5-methylcytosine restriction system comp \\
164 & 1423.17 & 1.53 & gi $\mid 229255650$ & hypothetical protein CochDRAFT_19730 \\
165 & 2024.66 & 1.53 & gi $\mid 229210424$ & alpha-phosphoglucomutase \\
166 & 1603.16 & 1.53 & gi $\mid 213963535$ & conserved hypothetical protein \\
167 & 2136.53 & 1.52 & gi $\mid 197736694$ & hypothetical protein FNP_1239 \\
168 & 2170.12 & 1.52 & gi $\mid 213962656$ & conserved hypothetical protein \\
169 & 1958.17 & 1.52 & gi $\mid 225023180$ & hypothetical protein EIKCOROL_00032 \\
170 & 1441.73 & 1.52 & gi $\mid 229255214$ & protease subunit of ATP-dependent protease \\
171 & 1786.80 & 1.51 & gi $\mid 18463955$ & replication protein \\
172 & 1655.44 & 1.51 & gi $\mid 42526889$ & V-type ATP synthase subunit E \\
173 & 1460.62 & 1.51 & gi| 34762313 & Carbamoyl-phosphate synthase large chain \\
\hline
\end{tabular}

401 peptide in CS group. And there were 199 among them has a greater differences which more than 1.5 times (173 without redundant proteins, Table 2).

\subsection{Gene ontology function analysis}

In total, $9194(80.16 \%)$ identified microbial leading proteins corresponded to at least one GO term using InterProScan and in-house Perl Scripts. The number of proteins was counted at GO level 2 of biological process, cellular component, and molecular function ontology, respectively (Fig. 7). Moreover, the proteins of two groups that corresponded to the GO term of biological process, cellular component, and molecular function ontology were counted. Then, Fisher's exact test was performed to compare the difference of the protein group number between the two groups. Based on a $p<0.05$ level, the GO terms with CS group included 35 in biological process ontology, 2 in cellular component, and 30 in molecular function ontology. The GO terms with CF group included 59 in biological process ontology, 17 in cellular component, and 30 in molecular function ontology (Fig. 8).

The count of proteins corresponding to GO terms of all samples were performed using in-house Perl and R scripts. With a $p<0.05,80 \mathrm{GO}$ terms (33 in biological process ontology, 5 in cellular component ontology, and 42 in molecular function ontology) were found in atleast 12 pair samples with high caries, while only $10 \mathrm{GO}$ terms ( 8 in biological process ontology and 2 in molecular function ontology) were found in the caries-free specimen. Then, we transformed the $p$-value with negative $\log 10$, and visualized them with heatmaps using R (Fig. 9).

\subsection{PRM verification}

Parallel reaction monitoring (PRM) mass spectrometry was used to verify the target peptides determined by the metaproteomic analysis and a pre-experiment, and the 171 candidate peptides of the target protein were subjected to LC-PRM/MS analysis. In total, 103 candidate proteins were quantified by LC-PRM/MS, including 3 proteins (hinf_c_1_1270, fnuc2539_c_1_361, cgin_c_10_1771) that were determined as the differential expressed protein candidates in the metaprotemics study. The Skyline analysis results of each candidate peptide were shown.

Meanwhile, 17 differential expressed peptide candidates were confirmed by the Mann-Whitney U test with a $p<0.05$ cutoff, 15 differential expressed peptide candidates were obtained by paired-samples $\mathrm{T}$ test with a $p<0.05$ cutoff, and 7 peptides in common (Table 6). 


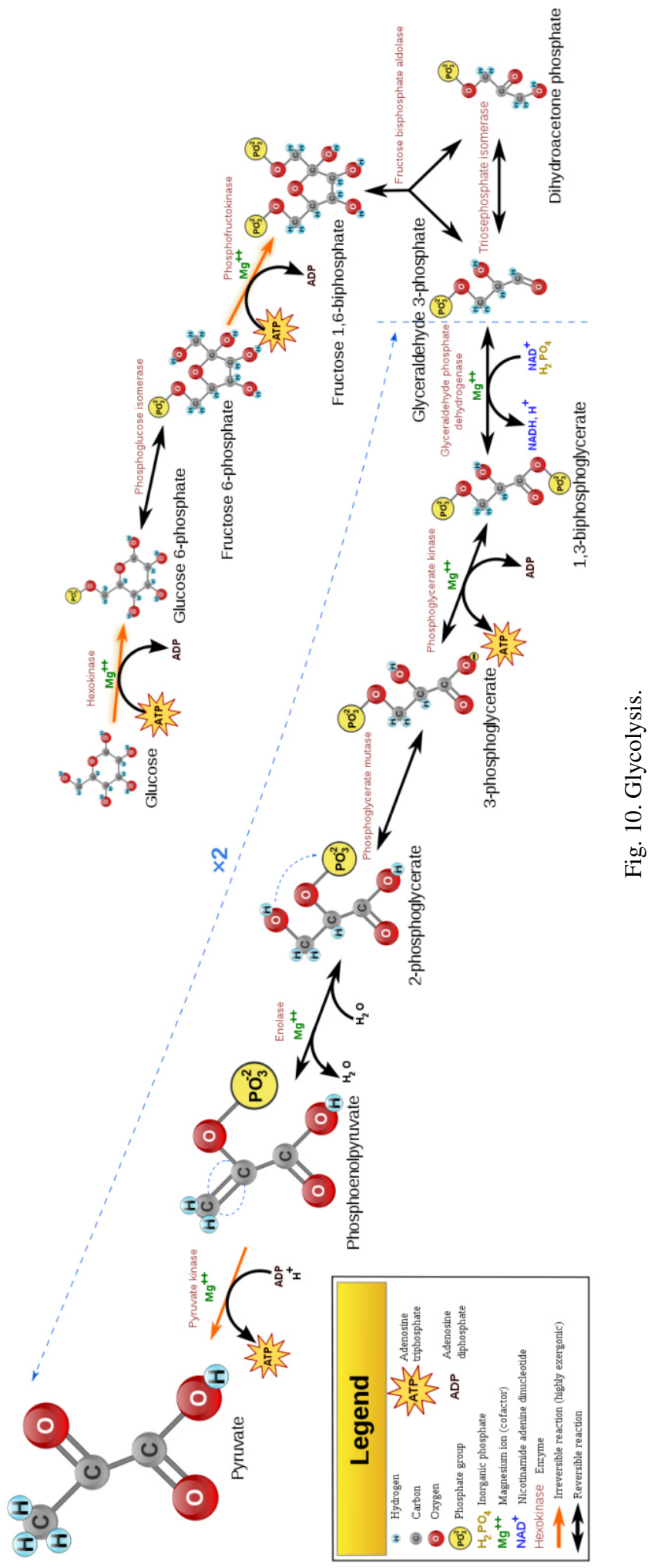




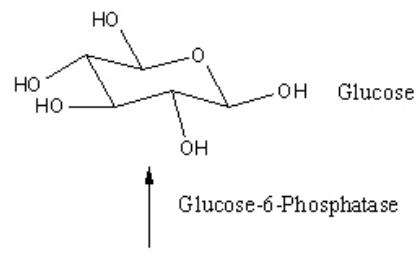

Glucose-6-Pho sphate

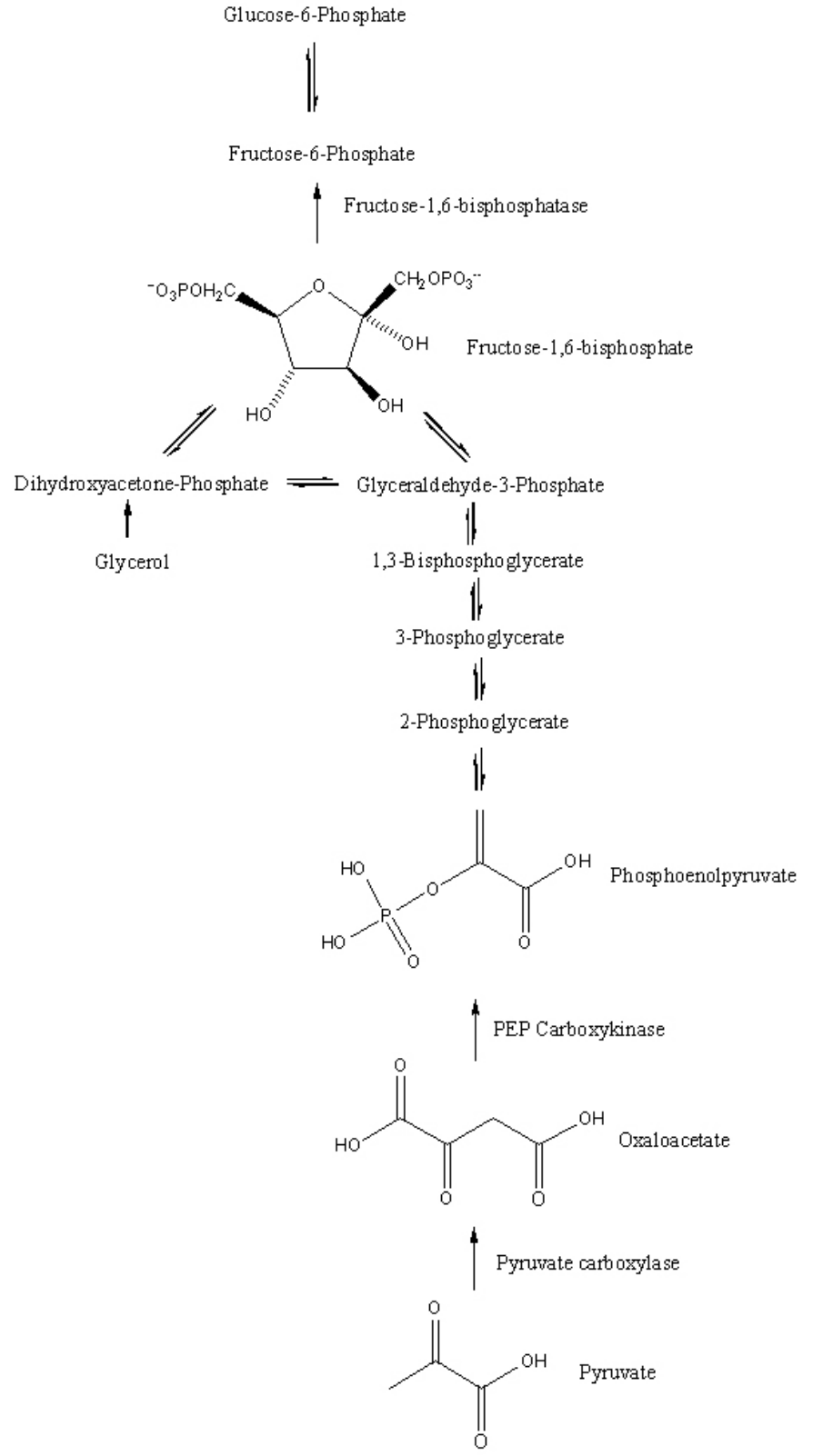

Fig. 11. Gluconeogenesis. 
Table 3

High expression $\mathrm{ABC}$ transporter data set of CS group $(P<0.05)$

\begin{tabular}{ccll}
\hline Num & Ratio & \multicolumn{1}{c}{ GI ID } & ID details \\
\hline 1 & 2.26 & gi $\mid 42525942$ & bacteriocin ABC transporter, bacteriocin-binding \\
2 & 2.20 & gi 42525700 & ABC transporter, ATP-binding protein \\
3 & 1.96 & gi 229210734 & nickel ABC transporter \\
4 & 1.86 & gi 42525831 & ABC transporter ATP-binding protein/ peptidase \\
5 & 1.85 & gi $\mid 197735467$ & ABC superfamily ATP binding cassette transporter \\
6 & 1.84 & gi 42526405 & ABC transporter, ATP-binding protein \\
7 & 1.69 & gi 42525700 & ABC transporter, ATP-binding protein \\
8 & 1.55 & gi $\mid 34764886$ & Export ABC transporter \\
9 & 1.44 & gi $\mid 197735439$ & ABC superfamily ATP binding cassette transpor \\
10 & 1.37 & gi $\mid 34763755$ & ABC transporter ATP-binding protein \\
11 & 1.39 & gi| 229211590 & ABC-type metal ion transport system \\
12 & 1.19 & gi 34763045 & ABC superfamily ATP binding cassette transpor \\
13 & 1.12 & gi 34763548 & Hemin transport system ATP-binding protein hmuV \\
\hline
\end{tabular}

Table 4

High expression $\mathrm{ABC}$ transporter data set of $\mathrm{CF}$ group $(P<0.05)$

\begin{tabular}{cccl}
\hline Num & Ratio & GI ID & ID details \\
\hline 1 & 1.32 & gi $\mid 229210852$ & ABC-type uncharacterized transport system \\
2 & 1.26 & gi $\mid 188994222$ & putative ABC transporter ATP-binding protein \\
3 & 1.18 & gi $\mid 42525832$ & ABC transporter, ATP-binding/permease protein \\
4 & 1.16 & gi $\mid 34763794.1$ & branched chain amino acid ABC superfamily ATP \\
\hline
\end{tabular}

\section{Discussion}

In this study, we initially used the method of macroproteomics to find the bacterial secretion proteins in caries-free children and children with high caries, with a total of 1735 peptides, including 603 statistically different peptides. Further bioinformatics study found that the proteins with differences in the expression were more than 1.5 times mainly concentrated in the glycolysis/glyneogenesis, pyruvate metabolism, citric acid circulation, $\mathrm{ABC}$ transporters, etc. We will discuss from two aspects - the pathways and the key proteins.

\subsection{Saccharolysis/sugar lyiogenesis}

\subsubsection{Glycolysis}

Saccharolysis (glycolysis) is the first step in the sugar metabolism process of all biological cells. During this process, a molecule of glucose undergoes a ten-step enzyme reaction to form two molecules of pyruvate with the formation of ATP (Figs 8-10). This suggests the presence of active sugar metabolism in the caries-causing plaque, presumably due to the highly expressed enzymes that use intracellular polysaccharide, mainly glycogen as a source of energy, resulting in tooth demineralization [6].

Phosphorylation of the phosphoric fructose (phosphorylation of fructose-6-phosphate) is the third step of glycolysis, further phosphorylation of $\mathrm{C}$ on 6-phosphate fructose initially produces 1,6-diphosphate fructose supplied by ATP. The reaction is catalyzed by phosphate fructose kinase (phosphofructokinase, PFK), which is an important speed limiting enzyme in the sugar aerobic oxidation process. Phosphoric transfer of phosphoenol pyruvate is the final reaction in glycolysis that involves the transfer of the high energy phosphorate group from phosphoroll pyruvate to ADP, and is catalyzed by pyruvate kinase, PK, which is another phosphorylation process at the substrate level. 


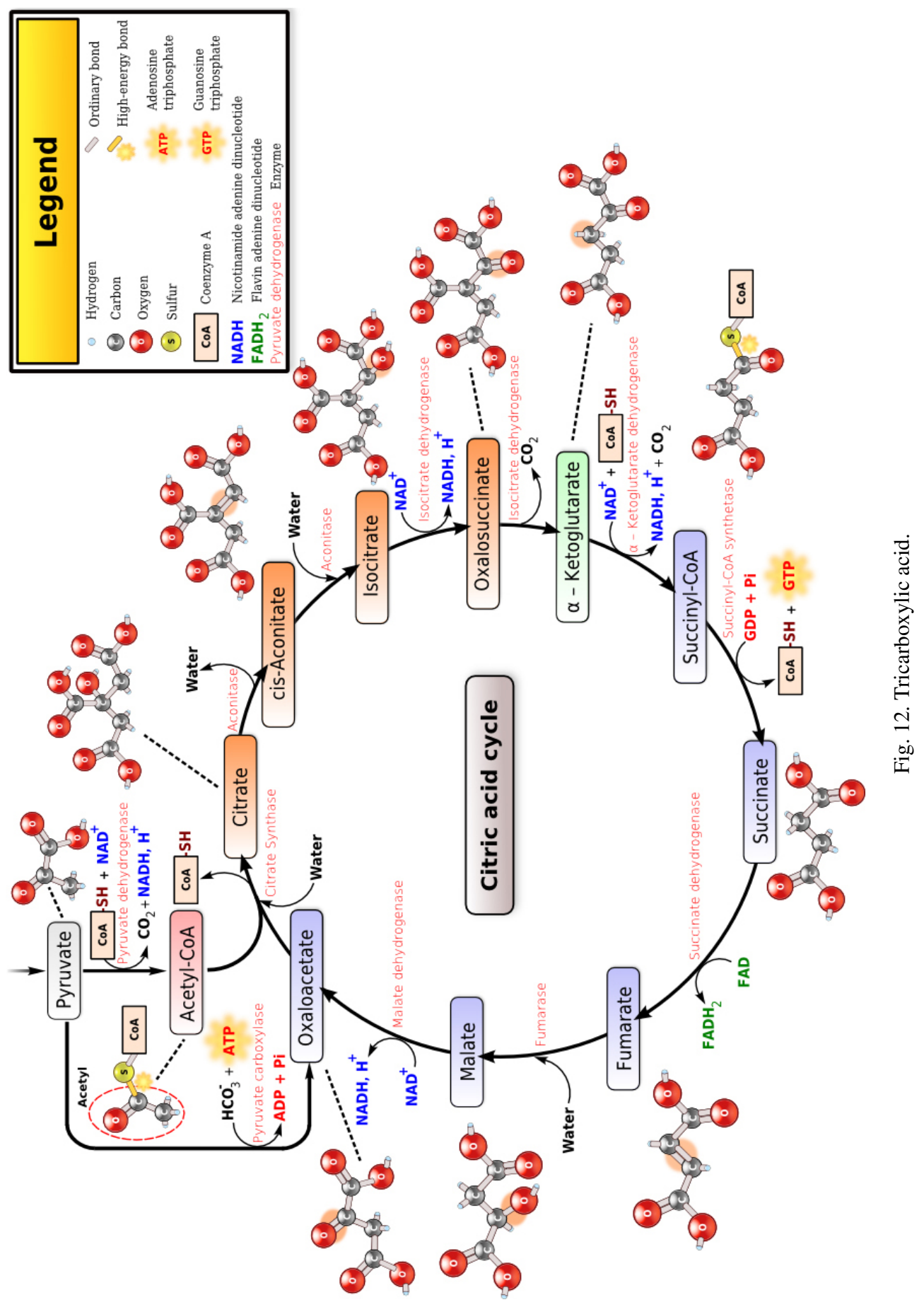


Table 5

Co expression $\mathrm{ABC}$ transporter data set of $\mathrm{CS} \& \mathrm{CF}$ group $(P>0.05)$

\begin{tabular}{|c|c|c|}
\hline Num & GI ID & ID details \\
\hline 1 & gi|197735467 & ABC superfamily ATP binding cassette transport \\
\hline 2 & gi|229212097 & ABC-type multidrug transport system \\
\hline 3 & gi|229212809 & ABC-type multidrug transport system \\
\hline 4 & gi $\mid 229210643$ & ABC-type oligopeptide transport system \\
\hline 5 & gi $\mid 42527941$ & $\mathrm{ABC}$ transporter, ATP-binding/permease protein \\
\hline 6 & gi| 229211946 & ABC-type cobalt transport system \\
\hline 7 & gi| 229211911 & ABC-type $\mathrm{Fe}^{3+}$ transport system \\
\hline 8 & gi $\mid 229211590$ & ABC-type metal ion transport system \\
\hline 9 & gi 42526433 & ABC transporter, ATP-binding/permease protein \\
\hline 10 & gi 42528282 & ABC transporter, ATP-binding/permease protein \\
\hline 11 & gi|42525789 & ABC transporter, ATP-binding/permease protein \\
\hline 12 & gi $\mid 42526418$ & $\mathrm{ABC}$ transporter, ATP-binding protein \\
\hline 13 & gi 42526693 & $\mathrm{ABC}$ transporter, ATP-binding protein \\
\hline 14 & gi $\mid 42525831$ & ABC transporter ATP-binding protein/peptidase \\
\hline 15 & gi $\mid 229210567$ & amino acid/amide $\mathrm{ABC}$ transporter membrane prot \\
\hline 16 & gi 19704374 & branched chain amino acid $\mathrm{ABC}$ transporter \\
\hline 17 & gi| 197736157 & dipeptide/oligopeptide/nickel $\left(\mathrm{Ni}^{2+}\right) \mathrm{ABC}$ supe \\
\hline 18 & gi| 228274621 & excinuclease $\mathrm{ABC}$ subunit $\mathrm{A}$ \\
\hline 19 & gi 42526877 & excinuclease $\mathrm{ABC}$ subunit $\mathrm{B}$ \\
\hline 20 & gi $\mid 42527978$ & excinuclease $\mathrm{ABC}, \mathrm{C}$ subunit \\
\hline 21 & gi $\mid 42527718$ & galactoside $\mathrm{ABC}$ transporter, $\mathrm{ATP}-$ binding protein \\
\hline 22 & gi $\mid 197736905$ & iron $\left(\mathrm{Fe}^{3+}\right)$ ABC superfamily ATP binding casse \\
\hline 23 & gi| 42526259 & iron compound $\mathrm{ABC}$ transporter \\
\hline 24 & gi 42526690 & iron compound $\mathrm{ABC}$ transporter \\
\hline 25 & gi $\mid 197736077$ & nickel $\left(\mathrm{Ni}^{2+}\right)$ ABC superfamily ATP binding cas \\
\hline 26 & gi 197736393 & possible nitrate/sulfonate/bicarbonate $\mathrm{ABC}$ su \\
\hline
\end{tabular}

Table 6

Candidate differential expressed peptides were confirmed by Mann-Whitney U test and paired-samples T test in common

\begin{tabular}{lccc} 
Peptide sequence & $p$-value with Mann-Whitney U test & $p$-value with paired-sample T test & Fold change \\
\hline VVEYVEKPVIVYR & $4.90 \mathrm{E}-02$ & $4.63 \mathrm{E}-02$ & 8.51 \\
YSFSTCYNSER & $3.56 \mathrm{E}-03$ & $4.40 \mathrm{E}-03$ & 5.21 \\
TAALENAAEGGFNKK & $2.19 \mathrm{E}-02$ & $5.22 \mathrm{E}-03$ & 4.33 \\
VVVEVLSQGK & $2.27 \mathrm{E}-02$ & $5.87 \mathrm{E}-03$ & 3.73 \\
LNNCPTSPR & $4.35 \mathrm{E}-02$ & $3.32 \mathrm{E}-02$ & 3.71 \\
VLDELTALR & $4.97 \mathrm{E}-02$ & $4.18 \mathrm{E}-02$ & 2.50 \\
SPEEAYEHAK & $4.91 \mathrm{E}-02$ & $2.51 \mathrm{E}-02$ & 2.14 \\
\hline
\end{tabular}

Reversible reactions in glycolysis include 7 steps: glucose phosphate isomerase is involved in the second step; heterogeneous reaction of glucose phosphate (isomerization of glucose-6-phosphate); participation in step 4 1.6-diphosphate pyrolysis reaction (i.e. cleavage of fructose 1, $6 \mathrm{di} / \mathrm{bis}$ phosphate from fructose-1, 6-Bisphosphate Aldoase (fructose-1, 6-bisphosphate aldolase); participation in step 6:3-glyceraldehyde phosphate oxidation reaction (oxidation of glyceraldehydes-3-phosphate); 3-glyceraldehyde phosphate dehydrogenase (glyceraldehyde 3-phosphate dehydrogenase); phosphorate kinase (phosphoglycerate kinase, PGK) participating in high energy phosphate bond transfer of step 1.3-diphosphate glyceric acid. These enzymes showed a high expression in the plaque fluid in both two groups. Studies show that the above catalytic enzymes participate in the sugar heterogeneous reaction at the same time. So, we speculate that both in caries-free or caries causogenic plaque, the glycolysis and sugar heterogeneous reaction can be accurately adjusted, so that the bacteria in the plaque can use the excess sugar in the form of glycogen as energy storage to meet their own energy needs. 

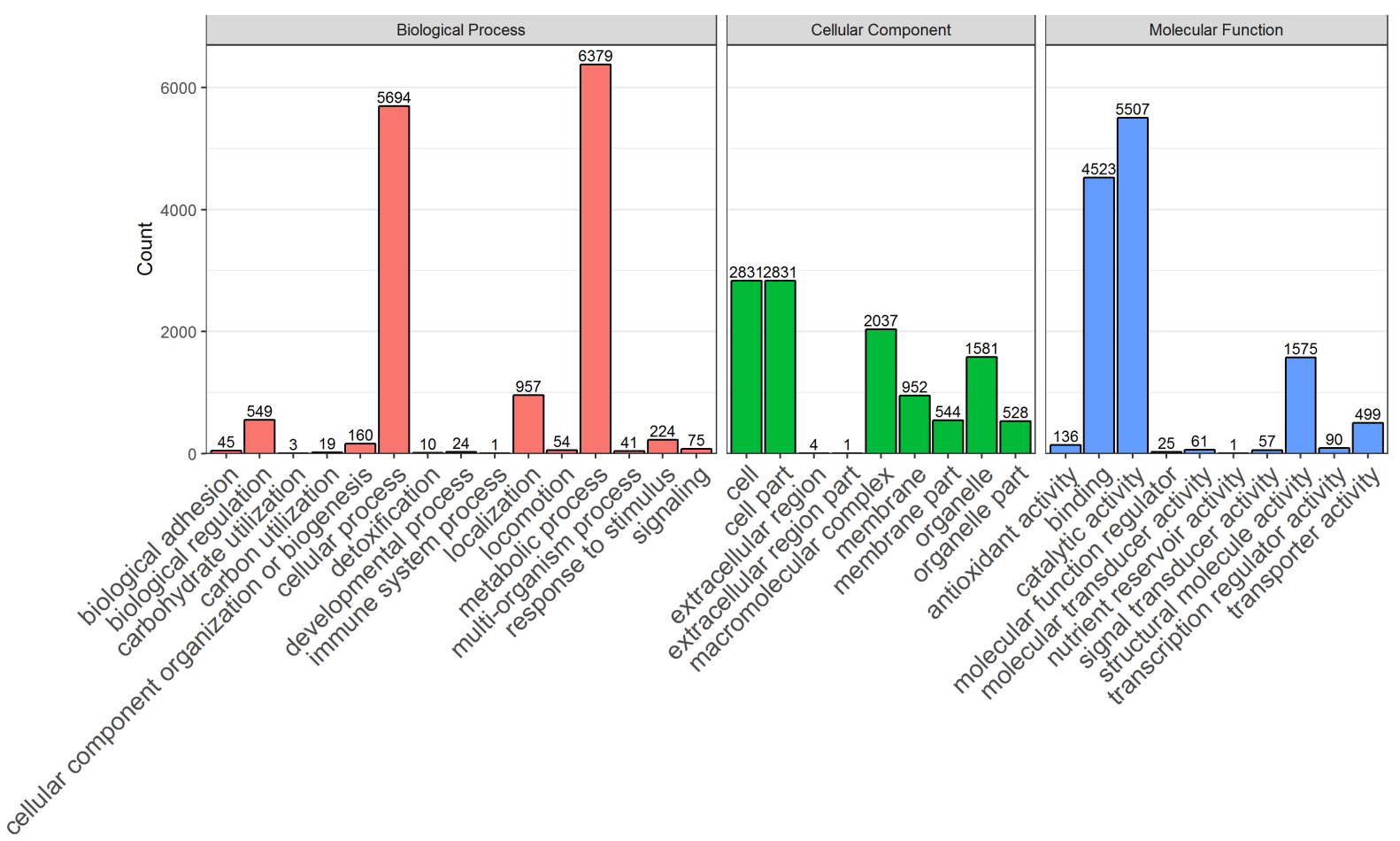

Fig. 13. A bar chart of protein count at GO level 2 of biological process, cellular component, and molecular function ontology using the 'ggplot2' package. The number markers at the bar were protein count of the GO term.

The final reversible reaction is step 2-phosphoglyceric acid, catalyzed by enolase, which was highly expressed in the CS group $(P<0.05$, ratio $=1.75)$, and mainly corresponds to the bacterial glycolysis pathway, suggesting that glycololysis plays an extremely important role in carie.

\subsubsection{Gluconeogenesis and $N A D^{+}$regeneration}

There are three-step reactions in glycolysis that are irreversible reactions that must be bypassed during sugar heterogenesis, at the cost of higher energy consumption (Fig. 11). The fructose-1,6-diphosphatase involved in this process was highly expressed in the CS group and the phosphoenlate-type pyruvate carboxylated kinase was expressed in both groups, suggesting that the sugar heterogenesis occured in both the mature and the pathogenic plaque and was precisely regulated.

$\mathrm{NAD}^{+}$can be regenerated by lactate dehydrogenase (lactate dehydrogenase, $\mathrm{LDH}$ ), ethanol dehydrogenase (Alcohol dehydrogenase, ADH), and NADH dehydrogenase. LDH is the key enzyme for synthetic lactic acid, and its biological effect is the key link in causing caries. S. mutans lacking LDH activity significantly reduced the caries in vivo in the restricted rodent model experiments [7-9]. However, there was no significant difference in the mean LDH activity of $S$. mutans in different caries-sensitive populations [10]. This experiment also found no significant difference in the LDH expression in children with no or high caries. But the lack of LDH has a lethal effect on the bacteria, since an LDH deficient strain results in intracellular NAD during aerobic growth ${ }^{+} / \mathrm{NADH}$ metabolic imbalance and accumulation of glycolysis toxic intermediates, killing the bacteria. The results of this experiment in turn confirms the idea that, whether there is caries or the absence of caries, there must be an active expression of LDH, which is one of the necessary conditions for the Streptococcus bacteria to survive. 


\subsection{Tricarboxylic acid circulation}

The cytoplasm of prokaryotes is the site of tricarboxylic acid circulation, but most enzymes are found in plaque fluid, including isocitrate dehydrogenase (isocitrate dehydrogenase, IDH) (Fig. 12), succinate dehydrogenase, malate dehydrogenase, succinyl-assisted A synthase, and $\alpha$-ketovaltarate dehydrogenase complex in the CS group are unknown.

The IDH superfamily is ancient and large, widespread in the three boundaries of life (archaea, bacteria and eukaryotes). IDH catalyzes isocitric acid to $\alpha$-ketopenta in tricarboxylic acid (TCA) cycle, bringing $\mathrm{NAD}^{+}$or the $\mathrm{NADP}^{+}$to NADH or a NADPH. It not only plays an important role in energy metabolism, amino acids and vitamin synthesis, but also plays a key regulatory role in the TCA circulation and the carbon flux distribution of acid bypass [11-14].

\subsection{ABC transporter protein}

This study identified more than 50 corresponding adenosine triphosphate binding box transporters (ATP-binding cassette transporter, $\mathrm{ABC}$ transporters) in children who were caries-free or with high caries. Associated with the transport of iron, nickel, cobalt ions, iron compounds, metal ions, oligopeptides, dipeptides, amino acids, branched chain amino acids, lactosidase, it is seen that $\mathrm{ABC}$ transporters are involved in various physiological functions of bacteria. It is worth noting that we identified 13 highlyexpressed $\mathrm{ABC}$ transporters in the CS group, 6 proteins expressed more than 1.5 times, while only 4 $\mathrm{ABC}$ transporters were highly expressed in the $\mathrm{CF}$ group and all were less than 1.5 times, suggesting that material transformation in the process of caries-causing transformation of bacteria. Among them, ABC transporter of the group CS was expressed 2.6 times high, which may be the potential target molecule for caries activity evaluation.

\subsection{Molecular partner}

This experiment identified 34 molecular companion peptide segments, belonging to the Hsp60 (GroEL) family, Hsp70 (DnaK) family, Hsp90 (Http pG) family, and Hspl00 (CIp) family. GroEL's E. coli is a homologous oligomer complex that plays an important role in the correct folding and assembly of newborn proteins and the recovery of degenerative proteins under thermal or chemical adversity. Although it has been determined that GroEL is located in the cytoplasm, the surface of some pathogens can express GroEL, and this is generally associated with the role the molecular partners play during adhesion [15]. GroEL expression was also detected in plaque fluid. It is speculated that the Hsp molecular companion, as the main antigen of most pathogens, may cause GroEL rearrangement on the bacterial cell membrane in the process of bacterial infection or under stress stimulation. Unlike the first two HSP, we found that HtpG was significantly upregulated in the CS group, but relevant studies showed that HSP90 synthesis speed and synthesis volume after stress were not significantly different than the above HSP, so its mechanism of cell protection needs to be further clarified.

\subsection{Phosphorylation modification}

In this experiment, the presence of two-component systems and Phosphotransferase system (PTS) was detected and consistently increased in expression in group CS, suggesting active protein phosphorylation modification and intercellular signaling in pathogenic biofilms.

The PTS system usually consists of five proteins including the enzyme I, enzyme (including three subunits of A, B and C) and phosphoolenol pyruvate (phosphoenolpyruvate, HPr). High expression of PTS system IIA, IIC in the CS group was also observed in this trial, indicating that the glucose intake within the flora was active during the occurrence of caries and development. 


\subsection{Bacterial phages}

At present, specific phages for bacteria such as Actinomyces, Actinobacillus Actinomycetecomitans, Actinomyces viscosus, Enterococcus faecalis (Actinomyces Actinobacillus actinomycetecomitans, Actinomyces viscosus, Enterococcus faecalis have been isolated in plaque and saliva respectively, In this experiment, eight phage-related proteins were detected in two groups, two of them (phages and microstructural proteins) were highly expressed in the high caries group. Although less data on this finding is available, some scholars have speculated on the potential prospect of bacteriophages in the caries prevention and treatment process [16-19]. Taking a phage as a plaque control method may be a new area.

\subsection{Membrane protein}

The outer membrane is the contact surface of the bacteria and the external environment, and its main components are lipid, lipoprotein and outer membrane protein. Outer membrane protein is the main component of the outer membrane, which plays an important role in material transport, information identification, cell adsorption, and outer membrane protein and secreted protein are also the first choice protein of vaccine antigens. A variety of high-expression of bacterial outer membrane protein, lipoprotein, and apolipoprotein were detected in this experiment, but its function in the occurrence and development of caries needs yet to be studied specifically.

\subsection{Other key proteins}

After PRM verification, we found some key proteins which may play an important role during the development of dental caries in children (Fig. 13), which are discussed below.

Our experimental results show that although PFK and PK are highly expressed in both CF, CS groups, it exceeds 1.5 times in the CS group, indicating that PEK and PK play an important role in the occurrence and development of caries, especially in bacterial caries, and also shows that the glycolysis process can provide energy for the life activity of bacterial cells and maintain the bacterial physiological function in mature plaque.

In addition, this experiment also found that glycan phosphate isomerase was highly expressed in the plaque fluid in children with high caries, indicating that this enzyme may play an important role in the plaque caries-causing process by promoting the effective energy generation of the plaque bacteria.

$\mathrm{ADH}$ is a zinc-containing metallicase widespread in human and animal liver, plant and microbial cells, with a broad substrate specificity to convert pyruvate produced by glycolysis into acetaldehyde and NAD and $\mathrm{NAD}^{+}$, thereby generating the energy needed for glycolysis. In this experiment, we found that ADH was highly expressed in the high caries group. It remains to be further studied, whether it also plays a role in the caries-induced transformation of plaque and the information exchange between bacteria.

Hydrohydrogenase (hydrogenase) is an important class of biological enzymes present in the microorganisms that catalyze the oxidation of hydrogen or hydrogen production from reduced protons. In our experimental results, the presence of iron hydrogenase and ferroxygen reduction protein was detected in both groups and significantly highly expressed in the high caries group, presuming that this may be one of the mechanisms where acid-producing and acid-resistant bacteria survive in the acid-induced plaque.

In conclusion, in the present study, we obtained 1804 peptides with quantitative information, including 395 in CF group, 30 in CS group, 1735 peptides in both the groups. The DeCyder ${ }^{\mathrm{TM}} \mathrm{MS}$ software conducted further statistics and analysis, and obtained 603 data sets of different peptide expression. The function of 391 peptides was unknown in this experimental dataset, and 47 peptides were highly 
expressed in the high caries group. Their specific function and their relationship with the caries are still uncertain. Nevertheless, macroproteomics, secretory proteomics and bioinformatics analysis has still provided a very good platform for our research, so that we could conduct a good comprehensive analysis of the proteins known to-date. Further research will be conducive to clarify the cause, and looking for disease-related biomarkers, which will be one of our future research directions.

\section{Acknowledgments}

This work is supported by the Shanghai Natural Science Foundation of China (grant number: 18zr1422300), the Innovative research team of high-level local universities in Shanghai (SSMUZDCX20180901), the Fundamental research program funding of Ninth People's Hospital affiliated to Shanghai Jiao Tong university School of Medicine (JYZZ139), and the Natural Science Foundation of Tibet Autonomous Region (XZ2019ZR-ZY43(Z)).

\section{Conflict of interest}

None to report.

\section{References}

[1] Corby PM, Lyons-Weiler J, Bretz WA, et al. Microbial risk indicators of early childhood caries. J Clin Microbiol. 2005; 43: 5753-5759.

[2] Li Y, Ge Y, Saxena D, Caufield PW. Genetic profiling of the oral microbiota associated with severe early-childhood caries. J Clin Microbiol. 2007; 45: 81-87.

[3] Lin Y, Qiu L, Gao X. Relationship between protein components in saliva and plaque fluid and caries susceptibility. Chinese Journal of Stomatology. 2002; 37: 39-42.

[4] Yao Y, Grogan J, Zehnder M, et al. Compositional analysis of human acquired enamel pellicle by mass spectrometry. Arch Oral Biol. 2001; 46: 293-303.

[5] Yao Y, Berg EA, Costello CE, et al. Identification of protein components in human acquired enamel pellicle and whole saliva using novel proteomics approaches. J Biol Chem. 2003; 278: 5300-5308.

[6] Liu Z. Oral biology. People's Health Publishing Company. Third edition.

[7] Hillman JD, Brooks TA, Michalek, et al. Construction and characterization of an effector strain of Streptococcus mutans for replacement therapy of dental caries. Infect Immun. 2000; 68: 543-549.

[8] Fitzgerald RJ, Adams BO, Sandham HJ, et al. Cariogenicity of a Lactate dehydrogenase-deficient mutant of Streptococcus mutans serotype c in gnotobiotic rats. Infect Immun. 1989; 57: 823-826.

[9] Hillman JD. Lactate dehydrogenase mutants of Streptococcus mutans: isolation and preliminary characterization. Infect Immun. 1978; 21: 206-212.

[10] Yang D, Liu T, Zhou X, et al. Preliminary study on LDH activity of Streptococcus mutans isolates from different caries sensitive populations. West China Journal of Stomatology. 2005; 23: 116-118.

[11] Zhu GP, Golding GB, Dean AM. The selective cause of an ancient adaptation. Science. 2005; 307: 1279-1282.

[12] Lunzer M, Mill ER SP, Felsheim R. The biochemical architecture of an ancient adaptive landscape. Science. 2005; 310 : 499-501.

[13] Ell-ington AD, Bull JJ. Changing the cofactor diet of an enzyme. Science. 2005; 310: 454-455.

[14] Jung IL, Kim SK, Kim IG. The RpoS-mediated regulation of isocitrate dehydrogenase gene expression in Escherichia coli. Curr Microbiol. 2006; 52: 21-26.

[15] Garduno RA, Garduno E, Hoffman PS. Surface-associated hsp60 chaperonin of Legionella pneumophila mediates invasion in a HeLa cell model. Infect Immun. 1998; 66: 4602-4610.

[16] Delisle AL, Nauman RK, Minah GE. Isolation of a bacteriophage for Actinomyces viscosus. Infection and Immunity. 1978; 20: 303-306. 
[17] Tylenda CA, Calvert C, Kolenbrander PE, Tylenda A. Isolation of Actinomyces bacteriophage from human dental plaque. Infection and Immunit. 1985; 49: 1-6.

[18] Yeung MK, Kozelsky CS. Transfection of Actinomyces spp. by genomic DNA of bacteriophages from human dental plaque. Plasmid. 1997; 37: 141-153.

[19] Bachrach G, Leizerovici-Zigmond M, Zlotkin A, Naor R, Steinberg D. Bacteriophage isolation from human saliva. Lett Appl Microbiol. 2003; 36: 50-3. 